\title{
Thirty percent of abstracts presented at dental conferences are published in full
}

DOI:

10.1016/j.jclinepi.2016.01.029

\section{Document Version}

Accepted author manuscript

Link to publication record in Manchester Research Explorer

\section{Citation for published version (APA):}

Hua, F., Walsh, T., Glenny, A-M., \& Worthington, H. (2016). Thirty percent of abstracts presented at dental conferences are published in full: a systematic review. Journal of Clinical Epidemiology, 75, 16-28.

https://doi.org/10.1016/j.jclinepi.2016.01.029

\section{Published in:}

Journal of Clinical Epidemiology

\section{Citing this paper}

Please note that where the full-text provided on Manchester Research Explorer is the Author Accepted Manuscript or Proof version this may differ from the final Published version. If citing, it is advised that you check and use the publisher's definitive version.

\section{General rights}

Copyright and moral rights for the publications made accessible in the Research Explorer are retained by the authors and/or other copyright owners and it is a condition of accessing publications that users recognise and abide by the legal requirements associated with these rights.

\section{Takedown policy}

If you believe that this document breaches copyright please refer to the University of Manchester's Takedown Procedures [http://man.ac.uk/04Y6Bo] or contact uml.scholarlycommunications@manchester.ac.uk providing relevant details, so we can investigate your claim.

\section{OPEN ACCESS}




\title{
Publication fate of abstracts presented at dental conferences: A systematic review and meta-analysis
}

\author{
Fang Hua, Tanya Walsh, Anne-Marie Glenny, Helen Worthington * \\ Cochrane Oral Health Group, School of Dentistry, The University of Manchester, \\ JR Moore Building, Oxford Rd., Manchester M13 9PL, UK \\ * Corresponding author. Tel.: +44 (0)161 3060237 \\ Email address: helen.worthington@manchester.ac.uk
}

\section{How to Cite:}

Hua F, Walsh T, Glenny AM, Worthington H. Thirty percent of abstracts presented at dental conferences are published in full: A systematic review. Journal of Clinical Epidemiology. 2016 Feb 4. pii: S0895-4356(16)00092-5. doi: 10.1016/j.jclinepi.2016.01.029. [Epub ahead of print]

doi: $10.1016 /$ j.jclinepi.2016.01.029.

PMID: 26854259

Please note that this is a pre-print version (before peer-review) for the purpose of self-archiving. Please download the final published version from the publisher's website: http://www.sciencedirect.com/science/article/pii/S0895435616000925 


\section{Abstract}

Objectives: To review the publication fate of abstracts presented at dental conferences, and investigate the association between full publication rate (FPR) and abstract characteristics, conference characteristics, and methodological quality of primary studies.

Study Design and Setting: PubMed, EMBASE and Google Scholar were searched from inception to November 2014 for studies that reported at least one FPR of abstracts presented at dental conferences, with a follow-up length of no less than 48 months.

Results: 16 studies involving 10,365 abstracts presented at 52 conferences were included. The pooled FPR was $29.62 \%$ [95\% confidence interval (CI): $22.90 \%, 36.81 \%$ ] for all presented abstracts, and 51.97\% (95\% CI: 43.19\%, 60.70\%) for randomized controlled trial abstracts. Abstract characteristics significantly associated with higher FPR included presence of statistical tests $(\mathrm{P}<0.001)$, oral presentation $(\mathrm{P}<0.001)$, basic science research $(\mathrm{P}=0.047)$ and financial support $(\mathrm{P}=0.009)$. Abstracts with positive $(\mathrm{P}=0.294)$ or statistically significant results $(\mathrm{P}=0.326)$ were not published more often than negative or nonsignificant abstracts, respectively. In multivariable meta-regression analysis, conferences held in Asia $(\mathrm{P}<0.001)$ and at a continental rather than national level $(\mathrm{P}<0.001)$ were significantly associated with higher FPR.

Conclusions: Less than one third of abstracts presented at dental conferences were published in full, more than 4 years after the presentation.

Keywords: Meeting abstracts; Publication bias; Publishing; Dentistry; Posters; Meta-analysis Running title: Publication fate of dental conference abstracts 


\section{What is new?}

\section{Key findings}

- Less than one third of abstracts presented at dental conferences were published in full, more than 4 years after the conferences.

- Abstracts presented orally, with statistical analyses, about basic science research, and those reported funding were significantly more likely to be published.

- No evidence of publication bias was found at this stage of research dissemination.

- The location and level of conferences were significantly associated with full publication.

\section{What this adds to what was known?}

- This study systematically reviewed all primary studies regarding the publication fate of abstracts presented at dental conferences and, by using multivariable meta-regression, provided insight into the roles of conference characteristics and methodological quality (of primary studies) as predictors of full publication.

- It adds to the body of evidence that many conference abstracts are never published in full.

\section{What is the implication and what should change now?}

- When analyzing predictors of full publication, future research regarding the publication fate of conference abstracts should control for the level and location of conferences. 


\section{Introduction}

Scientific conferences are important forums for early communication and dissemination of novel research findings. [1, 2] Often referred to and cited in meta-analyses [3] and clinical textbooks [4], abstracts presented at medical conferences can have a huge impact on the evidence base and clinical practice. However, conference abstracts are usually difficult to locate and access, present preliminary or partial results, lack details needed for critical appraisal, and have not undergone rigorous peer review. [4-8] Thus, full-length publications in peer-reviewed journals are commonly considered the expected outcome of conference presentations and endpoint of high-quality research. $[1,9,10]$

In publication fate studies, full publication rate (FPR), the proportion of abstracts presented at certain conferences that have resulted in full publication, and its predictors have been widely used as indicators of the quality of conferences and presented research, as well as measures of potential publication bias. [6, 11, 12] Two systematic reviews conducted during 2001 to 2003 reported that the FPR of abstracts presented at biomedical conferences ranged from $8 \%$ to $81 \%$, with a weighted mean value of $44.5 \%$; several abstract characteristics (positive results, oral presentation, randomized trial study design, basic science research) and conference characteristics (held in US, smaller size) were found to be significantly associated with higher FPR in univariate analyses. [13, 14]

In recent years, there have been many studies investigating the publication fate of abstracts presented at dental conferences. [15-23] These however, have not been analyzed in an integrated approach. In addition, although many studies with long follow-up supported a follow-up length of at least four to five years for publication fate research, $[2,15,22,24]$ previous systematic reviews regarding publication fate had no strict eligibility criterion in terms of follow-up length (minimum follow-up of included studies: eight months to two years). [13, 14, 25] Also no former research has studied the influence of methods used in a publication fate study on the FPR obtained. [13] This study uses multivariable meta-regression to analyze study-level factors (conference characteristics, methodological quality), and sets an inclusion criterion of having at least 48-month follow-up from the date of conference.

Therefore, the objectives of this review were to systematically review the publication fate (FPR and the time lag from conference to full publication) of abstracts presented at dental 
conferences, determined after at least 48 months after the conferences; and to investigate the association between FPR and abstract characteristics, conference characteristics, as well as the methodological quality of publication fate studies.

\section{Methods}

This review was written in accordance with the MOOSE [26] and PRISMA [27] guidelines for reporting systematic reviews. Unless specified as post-hoc, all methods were determined $a$ priori.

\subsection{Data sources and searches}

An electronic search of MEDLINE (via PubMed), EMBASE (via OVID) and Google Scholar was conducted on 23 November 2014, with guidance from the Trials Search Coordinator (Anne Littlewood) of Cochrane Oral Health Group. The full search strategy is shown in Appendix A. No restrictions for language or publication date were applied. In addition, after the initial study selection process, supplementary searches were performed by checking the reference lists of remaining key articles, and studies that cited these key articles, using Google Scholar, Scopus and Web of Science.

\subsection{Eligibility criteria}

We sought to identify all original studies investigating the publication fate of abstracts presented at one or more dental academic conferences. Studies were included if: (1) at least one FPR was provided or could be calculated (based on the study report or communication with the authors); (2) the conference being studied was on dentistry in general or any subspecialty of dentistry; (3) the determination of full publication was made at least 48 months after the abstract presentation date. If a study investigated multiple conferences, only conferences that met our eligibility criteria were included. Studies that only focused on abstracts presented by authors from certain specific institutions or geographic regions were deemed unrepresentative and therefore excluded. 
Study selection and data extraction were carried out by F.H. and then examined independently by one of the other reviewers. Any disagreement between reviewers was resolved by discussion. The following data were extracted and tabulated: (1) study information (author, publication date, full publication determination date, and whether focused on trial abstracts only); (2) conference characteristics (subject, level, date, location); (3) abstract characteristics (presentation type, significance of findings, usage of statistical analysis, research type, funding status, author geographic origin, and number of affiliations); (4) the number of abstracts presented (the denominator of FPR) and the corresponding number of full publications (the numerator); (5) the mean (or median) time to publication.

In terms of the significance of research findings, as summarized by Scherer et al [13], there have been two different definitions of "positive" results in publication fate research. One definition is statistically significant results in the direction of the experimental treatment as compared to the control treatment (with results not statistically significant defined as "neutral"); the other one is statistically significant results for either arm as compared to neutral results. For the sake of clarity, in this review by "positive" we mean the first definition.

Efforts to retrieve key missing data were made by contacting authors (e.g. end date of follow-up) and online searching (e.g. conference date). Most of the contacted authors kindly replied [16-20, 23]. When these efforts failed, relevant data were imputed using pre-specified methods (Appendix B). Following correspondence with authors we were able to confirm that for 12 subsamples (from 4 studies) the length of follow up was less than 48 months and were therefore subsequently excluded from the systematic review.

\subsection{Quality assessment}

A 3-component 8-item quality system (Table 1) was developed based on two similar reviews in medicine $[13,14]$. An overall quality score (range, $0-8$ ) was calculated with quality categorized as low (0-2 scores), moderate (3-5) and high (6-8). These scores and categorizations were only used for subsequent meta-regressions and sensitivity analyses, not any weight-assignment of data synthesis. The assessment was conducted by F.H. and one of the other reviewers independently and in duplicates. Disagreements between reviewers were resolved by discussion. 


\subsection{Data synthesis and consistency assessment}

The primary outcomes were the FPR (summary effect measure, Pooled FPR) and its association with abstract characteristics listed above (Risk Ratio). All statistical analyses were conducted using the Stata software (version 13.1; StataCorp, College Station, Tex). The Metaprop command, featuring a Freeman-Tukey double arcsine transformation, was used to estimate the pooled FPR and calculate relevant confidence intervals (CI). [28] A random-effects model (the DerSimonian and Laird method) [29] was adopted for meta-analyses. Between-study variability was evaluated using the $\mathrm{Q}$ and $\mathrm{I}^{2}$ statistics. In addition, all data syntheses were based on study-level data. For studies including several eligible subsamples, the overall data for these samples were calculated and used. As previous research suggested substantial difference in publication fate between trial abstracts and abstracts describing other types of research, [13] in this review, studies that only looked at trial abstracts were investigated separately.

\subsection{Assessment of publication bias}

For meta-analyses that included more than 10 studies, risk of publication bias was estimated by assessing the small study bias through visual inspection of funnel plot asymmetry and the Egger's test [30].

\subsection{Additional analyses}

We used random-effects meta-regression analyses to investigate the contribution of conference characteristics and methodological quality to heterogeneity. Univariable and multivariable models were fitted using the empirical Bayes method to estimate between-study variance. Pre-specified explanatory variables were the date, location, level and subject of conferences, as well as the methodological quality of studies. All variables with $\mathrm{P}<0.20$ in the univariable regressions were then included in the multivariable modelling. For the final model, only variables presenting $\mathrm{P}<0.05$ were considered significant. Since the value of these variables differs among substudy samples, all meta-regressions were performed on subsample-level data.

In sensitivity analyses, we examined the pooled FPR by excluding all studies/subsamples categorized as "low quality", and by including only studies/subsamples that have a follow-up length no less than 60 months. In addition, we carried out a post hoc sensitivity analysis excluding 
studies that only included abstracts of a certain presentation type (poster or oral). For meta-regression analyses, we intended to test the robustness of our results by using robust variance estimation (RVE) [31] with small sample corrections [32], which can account for potential clustering (hierarchical) effects among subsamples from the same paper.

\section{Results}

The electronic searches initially yielded 1958 records. After removal of duplicates, 1628 unique items were screened on the basis of title and abstract. Among these, 1607 were excluded due to clear irrelevance, leaving 21 for full text review. A further five articles and 12 subsamples were excluded because they did not fulfill our criteria regarding follow-up length and representativeness. No eligible study was found through supplementary hand and citation searches. Therefore, 16 studies (45 subsamples) [15-23, 33-39] were included for qualitative and quantitative synthesis (Figure 1).

\subsection{Study characteristics}

Of the 16 included studies, 14 were in English, 1 in Portuguese [38], and 1 in Chinese [39]. All of them had a cohort design. A total of 52 independent conferences and 10,365 abstracts were included. The conferences were held from 1980 to 2007, and about half of them (27) were on dentistry as a whole rather than a certain dental specialty. 15 studies (i.e. 42 subsamples) had no restriction on the study design of included abstracts, while 1 study (3 subsamples) was focused on trial abstracts only [23]. All included studies reported the full publication rate, 11 of them provided the mean or median time to publication. Additionally, one study was identified in the form of abstract, but we retrieved its unpublished full-text from the original researcher [23].

\section{(Table 2)}

\subsection{Quality assessment}

In general, the overall quality of included research was moderate. Of the 45 subsamples included, 5 were low quality, 3 were high quality, and the rest were moderate quality. Quality scores ranged from 2 to 7 , with a median of 4 (mean: 3.76). None of the included studies reported contacting the original authors for confirmation of no full publication. Only 5 studies (14 
subsamples) searched at least two databases to identify full publications. Only 8 studies (15 subsamples) checked and included full publications that were published before the conference. In terms of presentation type, one study ( 8 subsamples) only investigated oral presentation abstracts [18], while another study (two subsamples) only looked at poster abstracts [19]. (Table 2)

\subsection{Full publication rate}

Based on 15 studies, the pooled overall FPR of abstracts presented at dental conferences was 29.62\% (95\% CI: 22.90\%, 36.81\%; $\left.\mathrm{P}_{\text {effect }}<0.001\right)$. The $\mathrm{I}^{2}(98.1 \%)$ and $\mathrm{Q}(\mathrm{P}<0.01)$ values suggested a high level of heterogeneity (Figure 2). Although asymmetry was found in the funnel plot (Appendix C), the result of Egger's test [30] ( $\mathrm{P}=0.392)$ indicated no evidence of small study bias.

\subsection{Association between abstract characteristics and full publication}

Table 3 summarizes the results of all meta-analyses regarding association. Relevant forest plots can be found in Appendix D.

Two studies $[16,19]$ compared the FPR of abstracts with and without positive results. Based on these, reporting positive results was not associated with FPR ( $R R=0.80$; 95\% CI: 0.53, 1.21; $\left.\mathrm{P}_{\text {effect }}=0.294 ; \mathrm{I}^{2}=0.0 \%\right)$. Three studies $[15,16,19]$ investigated the association between FPR and the statistical significance of results. Again, statistical significance was not significantly associated with full publication ( $R R=0.87 ; 95 \%$ CI: $\left.0.65,1.15 ; \mathrm{P}_{\text {effect }}=0.326 ; \mathrm{I}^{2}=68.5 \%\right)$. However, abstracts which presented statistical tests were 2.02 (RR; 95\% CI: 1.54, 2.65; $\mathrm{P}_{\text {effect }}<0.001 ; \mathrm{I}^{2}=0.0 \%$ ) times more likely to be published in full than those that did not. While among those abstracts with statistical tests, no significant difference in FPR was found between those using analytical statistics and those using only descriptive statistics $\left(\mathrm{RR}=1.44 ; 95 \% \mathrm{CI}: 0.59,3.53\right.$; $\mathrm{P}_{\text {effect }}=0.424$; $\left.\mathrm{I}^{2}=88.3 \%\right)$.

In terms of presentation type, results from 5 studies $[15-17,36,37]$ indicated that abstracts presented orally were $51 \%\left(\mathrm{RR}=1.51 ; 95 \% \mathrm{CI}: 1.29,1.76 ; \mathrm{P}_{\text {effect }}<0.001 ; \mathrm{I}^{2}=58.4 \%\right)$ more likely to be published in full length than those presented in poster sessions.

Four studies $[16,17,20,39]$ investigated the association between FPR and research type. Abstracts describing basic science research were 49\% (RR=1.49; 95\% CI: 1.01, 2.22; $\mathrm{P}_{\text {effect }}=0.047$; 
$\left.\mathrm{I}^{2}=86.5 \%\right)$ more likely to be published in full than those describing clinical research.

In addition, results of two studies $[16,19]$ indicated that abstracts reporting funding sources were $42 \%\left(\mathrm{RR}=1.42 ; 95 \% \mathrm{CI}: 1.09,1.84 ; \mathrm{P}_{\text {effect }}=0.009 ; \mathrm{I}^{2}=0.0 \%\right)$ more likely to result in full publication than abstracts that did not report funding.

Based on two studies $[15,16]$ which reported FPR by the authors' continent of origin, no association was found. The FPR of abstracts presented by European authors (RR=1.22; 95\% CI: $0.80,1.87 ; \mathrm{P}_{\text {effect }}=0.361 ; \mathrm{I}^{2}=88.0 \%$ ) were not significantly different from those presented by authors out of Europe. Likewise, the FPR of abstracts presented by Asian authors ( $R R=0.95 ; 95 \%$ CI: $0.82,1.10 ; \mathrm{P}_{\text {effect }}=0.473 ; \mathrm{I}^{2}=0.0 \%$ ) was not significantly different from those presented by authors out of Asia.

Several other abstract characteristics were also investigated in the included studies. However, due to inadequate data, these could not be reviewed with meta-analyses. In Dahllof et al's study [17], abstracts of RCTs were 2.05 (RR; 95\% CI: 1.51, 2.79) times more likely to be published than those describing studies of other designs, while abstracts of case reports were $56 \%$ ( $R R=0.44 ; 95 \%$ CI: $0.29,0.68)$ less likely to be published than those of other types of studies. Galang et al [19] reported that the FPR of abstracts presented by multiple affiliations was significantly higher than that of abstracts presented by a single affiliation ( $R R=2.16 ; 95 \% \mathrm{CI}: 1.28,3.62)$. They also found that the FPR of abstracts describing experimental research was not significantly different from that of abstracts describing observational research $(\mathrm{RR}=1.24 ; 95 \% \mathrm{CI}: 0.78,1.98)$. Livas et al [15] compared the abstracts of five different types of author affiliation and found no significant difference in FPR (Chi-square, $\mathrm{P}=0.08)$.

\subsection{FPR of trial abstracts and associated abstract characteristics}

Only one study [23] reported the FPR of all trial abstracts (37.98\%; 95\% CI: 31.66\%, 44.74\%) and controlled clinical trial (CCT) abstracts (28.91\%; 95\% CI: 21.76\%, 37.28\%). However, two studies $[17,23]$ reported the FPR of randomized controlled trial (RCT) abstracts, and the pooled estimate was 51.97\% (95\%CI: 43.19\%, 60.70\%; $\left.\mathrm{P}_{\text {effect }}<0.001 ; \mathrm{I}^{2}=0.0 \%\right)$. (Appendix E)

Among abstracts that describe trials, Spencer et al [23] found no significant association between FPR and the statistical significance of results ( $R R=1.35 ; 95 \%$ CI: 0.87, 2.08). However, trial abstracts with clear statistical reporting were two times more likely to result in full 
publication than those with unclear statistical reporting ( $\mathrm{RR}=2.05$; 95\% CI: 1.37, 3.09). Additionally, the FPR of orally presented trial abstracts was also significantly higher than that of those presented as posters ( $\mathrm{RR}=1.82 ; 95 \% \mathrm{CI}: 1.29,2.56)$.

\subsection{Time to full publication}

A total of 9 studies reported either the mean or median duration of time to publication which was based on a follow-up of longer than 48 months. Based on 7 of these [15-17, 19, 21, 22, 36], the mean time to publication ranged from 15.8 to 48.0 months, with a median of 23.4 months and overall mean of 24.8 months. Based on three studies [17, 19, 37], the median time to publication ranged from 10 to 18 months, with the overall median being 18 months. Besides, for trial abstracts only, Spencer et al [23] reported a median time to publication of 20 months.

\subsection{Meta-regression analyses}

Only 42 out of the 45 included subsamples were used in meta-regression analyses, because the other three subsamples [23] were focused exclusively on trial abstracts. In the univariable meta-regression analyses, higher FPR was found to be associated with conferences held in Asia ( $\mathrm{P}=0.002)$, at a continental level $(\mathrm{P}<0.001)$, regarding orthodontics $(\mathrm{P}=0.004)$, as well as a higher methodological quality score $(\mathrm{P}=0.006)$. All variables showed a $\mathrm{P}$ value below 0.2. (Table 4)

Due to collinearity between conference level and conference subject, the latter was excluded from multi-variable modelling. The final model can explain $70.81 \%$ (adjusted $\mathrm{R}^{2}$ ) of the heterogeneity in FPR. Only conference location and level remained significant predictors of FPR. Conference location in Asia $(\mathrm{P}<0.001)$ and a continental conference level $(\mathrm{P}<0.001)$ were found to be associated with higher FPR. (Table 4)

\subsection{Sensitivity analyses}

Among the included subsamples, 5 were scored as low quality in the quality assessment. When these were excluded, the pooled overall FPR only increased slightly to $31.01 \%$ (95\% CI: $23.85 \%, 38.64 ; \mathrm{P}_{\text {effect }}<0.001 ; \mathrm{I}^{2}=98.17 \%$ ). For 8 subsamples, the follow-up length was shorter than 60 months. When these were excluded, the pooled overall FPR $(29.75 \%$; $95 \%$ CI: $22.80 \%$, $37.20 \% ; \mathrm{P}_{\text {effect }}<0.001 ; \mathrm{I}^{2}=97.81 \%$ ) was nearly the same as when they were included. In addition, 
two studies (10 subsamples) only included abstracts of one presentation type (either poster or oral). Again, exclusion of these resulted in a very similar pooled FPR (30.13\%; 95\% CI: 22.68, 38.14; $\mathrm{P}_{\text {effect }}<0.001 ; \mathrm{I}^{2}=98.30 \%$ ). Further, if all of the above mentioned studies/subsamples were excluded, the pooled FPR (31.00\%; 95\% CI: 22.73\%, 39.92\%; $\left.\mathrm{P}_{\text {effect }}<0.001 ; \mathrm{I}^{2}=98.22 \%\right)$ remained largely unchanged. According to Egger's [30] tests (P value range, 0.301 to 0.461 ), no evidence of small study bias was found for all the above syntheses.

Due to limited number of included studies and thus insufficient degrees of freedom, the robust variance estimation method could not be used to examine our meta-regression results.

\section{Discussion}

\subsection{FPR and time to publication}

Nowadays it is a common belief that nonpublication, especially of those studies that involve human subjects, is unethical and should be considered as one form of scientific misconduct. [40, 41] However, based on primary studies available, our review suggests that only $29.6 \%$ of all abstracts presented at dental conferences resulted in full-publication. Although the situation was better for abstracts describing RCTs, still only $52.0 \%$ of them were published in full. These figures appear slightly lower than the FPRs in Scherer et al 's systematic review regarding the publication fate of abstracts presented at biomedical conferences (weighted mean: $44.5 \%$ overall, $63.1 \%$ for RCT abstracts) [13]. However, readers should note the methodological differences between their review and this one. First, the primary studies that Scherer et al [13] included have a much shorter length of follow-up (minimum, 24 months; median, 45 months) than ours (48 months; 76 months), which may lead to underestimation of FPRs. Second, when calculating the overall FPR, they did not exclude those studies that only looked at RCT abstracts, making the meaning of their overall FPR different from ours.

Among the included studies of this review, the mean time to full publication ranged from 15.8 to 48.0 months, with the overall mean being 24.8 months. These figures might indicate existence of substantial "time lag bias" as, for abstracts that resulted in full-publication, a large proportion was not published within 30 months after presentation [42]. Excessive time lag is deleterious because it can lead to delayed appearance of research findings and depletion of the available evidence pool. Delayed publications also tend to become obsolete as they are often 
superseded by more recent research. [42] In addition, longer time lag was found to be significantly associated with more inconsistencies between presented abstracts and their corresponding full publications. [4, 11] In Scherer et al [13], the overall mean time lag (18.4 months) was half a year shorter than our result. But again, it is hard to determine whether this is due to a true difference between dentistry and other biomedical specialties, or the fact that studies included in their review had shorter follow-up length.

\subsection{Reasons for nonpublication}

An understanding of the reasons for nonpublication is crucial for interpreting the results of publication fate research. Previous surveys of authors whose conference abstracts were not published in full showed that only $20 \%$ [43] to $64.3 \%$ [1] of the authors actually submitted their presented abstracts to journals for consideration. A recent systematic review, based on 27 survey studies in biomedicine, showed that "lack of time" has consistently been the most frequently reported reason (weighted mean, 30.2\%) and most important reason (38.4\%) for not publishing presented abstracts in full. Other reasons like "publication not an aim", "incomplete study", "low priority" and "trouble with co-authors" were also frequently stated. On the other hand, reporting of reasons related to journal editors was uncommon. "Negative results" and "expect journal rejection" were only mentioned by $4.4 \%$ and $11.2 \%$ of the unpublished authors, respectively. [44] These findings all suggest that authors (nonsubmission), not the journal publication process (rejection), were the main barrier to full publication of presented abstracts.

Unfortunately, none of the included studies in this review surveyed unpublished authors regarding their reason for nonpublication. Corry [33] analyzed the publication history of unpublished authors, and found that about $28.5 \%$ of them did not publish any article during the first four to five years after abstract presentation. This could be an indirect evidence of "lack of time for research" or "publication not an aim", but due to the study design no solid conclusion could be drawn. It remains to be seen whether the reasons for nonpublication are the same between researchers in dentistry and those in other medical specialties.

\subsection{Abstract characteristics and FPR}

\subsubsection{Significance of research findings (publication bias)}


One commonly used definition of publication bias is "the tendency on the parts of investigators, reviewers, and editors to submit or accept manuscripts for publication based on the direction or strength of the study findings". [45] The existence of such publication bias has been well proven by numerous primary studies and systematic reviews regarding publication fate. [13, 14, 25] In Scherer et al [13], abstracts with positive results were 17\% (RR=1.17; 95\% CI: 1.02 to 1.35) more likely to be published in full than those with negative results; abstracts with statistically significant results also had a higher FPR than those with no statistical significance $(\mathrm{RR}=1.30 ; 95 \% \mathrm{CI}: 1.14$ to 1.47$)$.

However, in this review, neither positive ( $\mathrm{RR}=0.80 ; 95 \% \mathrm{CI}: 0.53,1.21)$ nor statistically significant ( $R R=0.87 ; 95 \%$ CI: 0.65 to 1.15$)$ results were significantly associated with higher FPR. This phenomenon is further confirmed by Spencer et al [23] who found that the publication fate of dental trial abstracts was also not associated with statistical significance $(\mathrm{RR}=1.35 ; 95 \% \mathrm{CI}$ : 0.87 , 2.08). These findings indicate that, at this stage of dental research dissemination (from abstract presentation to full publication), no evidence of publication bias was found.

One possible explanation for the difference between our findings and previous research is that publication bias occurred at an earlier stage, before the presentation of abstracts at conferences. [25] The fact that, in the relevant included studies [16, 19], the number of positive abstracts (452) were 8.5 times that of negative abstracts (53) might be an indirect evidence. However, without data regarding the results of abstracts before submission to dental conferences, this evidence is no better than speculation. To our knowledge, only one study analyzed abstracts submitted to a dental conference [46], and unfortunately it did not look at the significance of abstract results. Further research regarding the publication fate of dental studies in earlier phases of research dissemination (e.g. since the inception or registration of trials) is needed.

An alternative explanation is the influence of follow-up length on publication bias. When studying the publication fate of abstracts presented at an oncology meeting, Krzyzanowska et al [47] found that abstracts with statistically significant results were published significantly sooner than abstracts with nonsignificant results. If this phenomenon is true across all medical specialties, then by setting a reasonable inclusion criterion regarding follow-up length, our review was not biased by primary studies with overly short follow-up which can lead to underestimation of the FPR of nonsignificant results. 


\subsubsection{Other abstract characteristics}

The results of this review suggest that abstracts presented orally $(\mathrm{RR}=1.51 ; 95 \% \mathrm{CI}: 1.29$, 1.76), describing basic science research ( $R R=1.49 ; 95 \% \mathrm{CI}: 1.01,2.22)$, and reporting financial support (RR=1.42; 95\% CI: $1.09,1.84)$ were published significantly more often; while the FPR of abstracts by European authors (RR=1.22; 95\% CI: 0.80, 1.87) was not significantly different with that of those by authors from the rest of the world. These findings are in keeping with the systematic review by Scherer et al [13].

In addition, our review also suggests that presence of statistical tests was significantly associated with higher FPR ( $\mathrm{RR}=2.02 ; 95 \% \mathrm{CI}: 1.54,2.65)$. Similarly, trial abstracts with clear statistical reporting were significantly more often published ( $R R=2.05 ; 95 \% \mathrm{CI}: 1.37,3.09)$. These have not been reported in previous reviews. Possible reasons for less publication of abstracts without statistics might include the methodological shortcomings of the underlying studies [48], or associated author perceptions such as "incomplete study" or "publication not an aim" [44].

\subsection{Conference characteristics and FPR}

Using multivariable meta-regression analysis, we found that the location and level of conferences were significant predictors of FPR. Conferences held in Asia (reference: North America) and at a continental level (reference: national) had significantly higher FPR. Knowing that full publication of conference abstracts is mainly determined by factors related to abstract authors [44], our finding might be explained by a higher level of motivation to publish among attendees of those conferences held in Asia and at continental level. Readers should note that for the category of Asia, only one study from China [39] was available and included. It has been well reported that due to the current career promotion and employment systems, the pressure to publish is exceptionally high for doctors in China. $[49,50]$ Therefore, our finding regarding conference location may not be generalized to other countries in Asia.

\subsection{Methodological quality and FPR}

The overall methodological quality of studies included in this review was deemed moderate. However, the performance of these studies in the ascertainment of full publication was relatively 
poor, rendering our pooled FPR possibly underestimated. Correspondence with the authors of unfound articles for confirmation of nonpublication is an important procedure, and has been used by many similar studies in other medical specialties. After obtaining feedback from abstract authors, the FPR in these studies increased by $2.5 \% \sim 15.5 \%$ (response rate, $35 \% \sim 65 \%$ ). $[1,47,51]$ Unfortunately, in the present review, none of the included studies contacted abstract authors. This is probably because abstract books of dental conferences often do not provide the correspondence details of authors, although reporting of such information is required by guidelines such as the CONSORT for Abstracts [52].

In univariable meta-regression analysis, methodological quality score was a significant predictor of higher FPR, explaining $16 \%$ of the between-study variability. However, such significant association was not shown in multivariable meta-regression, suggesting that conference level and location had a greater influence on FPR.

\subsection{Limitations and strengths}

Our review is limited by the number and quality of available primary studies. Firstly, we were not able to investigate the association between FPR and other abstract characteristics, such as the language, quality, and level of evidence, $[9,13]$ because no study in dentistry had looked at these. Even for characteristics that we have reviewed, data were only available from 1 to 5 studies. More primary research on the predictors of dental abstracts' publication fate is needed. Secondly, due to limited number of studies available, in meta-regression analyses, the association between methodological quality and FPR was not studied separately for each quality characteristic (e.g. author contact and sample size). For the same reason, we could not use the robust variance estimation (RVE) to take into account potential hierarchical effects caused by subsamples from the same study. The RVE is a novel and appealing approach to addressing "correlated effects" and "hierarchical effects" in meta-regressions, which does not require information about the covariance structure of dependent effect size estimates. However, for RVE to perform well, at least 40 clusters and an average of five effect sizes per cluster are needed. [31, 32] Therefore, the meta-regression results (confidence intervals and $\mathrm{P}$ values) in this review should be interpreted with caution, and be revisited with RVE in the future when more studies are available.

Despite these limitations, this review has several strengths. It is the first of its kind to: (1) use 
the Metaprop command to pool FPR and calculate heterogeneity; (2) use univariable and multivariable meta-regression analyses to study potential predictors of FPR; (3) investigate the association between FPR and the methodological quality of publication fate study; (4) study the influence of conference level on FPR; and (5) summarize relevant research evidence in the field of dentistry.

\subsection{Implications for future research}

When studying predictors of FPR, future systematic reviews and primary studies where abstracts from multiple conferences are included, should control for the level and location of conferences. Whenever it is possible, we recommend future systematic reviews use multivariable RVE meta-regression [31,32] to study the influence of abstract, conference and methodological characteristics on full publication. To avoid aggregate bias (for analysis of abstract characteristics), an "individual participant data" meta-analysis might be the ideal design.

\section{Conclusions}

To summarize, less than one third of abstracts presented at dental conferences were published as full publications, more than 4 years after the conferences. Abstracts presented orally, with statistical analyses, about basic science research, and those reported funding were significantly more likely to be published. However, no evidence of publication bias was found at this stage of research dissemination. In addition, the location and level of conferences were significant predictors of full publication. 


\section{Acknowledgements}

The authors would like to thank Professor Elizabeth Tipton (Teachers College, Columbia University) for answering our questions regarding robust variance estimation, Anne Littlewood (School of Dentistry, University of Manchester) for assistance with literature searches, and all of the authors who responded to our requests regarding the unreported data of their studies.

Funding: F.H. is a recipient of the President's Doctoral Scholar Award from The University of Manchester, but this study had no explicit funding. The funding source had no involvement in the study design, collection, analysis and interpretation of data, preparation of the manuscript, or in the decision to publish.

\section{Conflict of interest}

None. 


\section{References}

[1] Sprague S, Bhandari M, Devereaux PJ, Swiontkowski MF, Tornetta P, 3rd, Cook DJ, et al. Barriers to full-text publication following presentation of abstracts at annual orthopaedic meetings. The Journal of bone and joint surgery American volume. 2003;85-A:158-63.

[2] Jasko JJ, Wood JH, Schwartz HS. Publication rates of abstracts presented at annual musculoskeletal tumor society meetings. Clinical orthopaedics and related research. 2003:98-103.

[3] Cook DJ, Guyatt GH, Ryan G, Clifton J, Buckingham L, Willan A, et al. Should unpublished data be included in meta-analyses? Current convictions and controversies. Jama. 1993;269:2749-53.

[4] Bhandari M, Devereaux PJ, Guyatt GH, Cook DJ, Swiontkowski MF, Sprague S, et al. An observational study of orthopaedic abstracts and subsequent full-text publications. The Journal of bone and joint surgery American volume. 2002;84-A:615-21.

[5] Marx WF, Cloft HJ, Do HM, Kallmes DF. The fate of neuroradiologic abstracts presented at national meetings in 1993: rate of subsequent publication in peer-reviewed, indexed journals. AJNR American journal of neuroradiology. 1999;20:1173-7.

[6] Greenberg D, Wacht O, Pliskin JS. Peer review in publication: factors associated with the full-length publication of studies presented in abstract form at the annual meeting of the Society for Medical Decision Making. Medical decision making : an international journal of the Society for Medical Decision Making. 2008;28:938-42.

[7] Hopewell S, Clarke M, Askie L. Reporting of trials presented in conference abstracts needs to be improved. Journal of clinical epidemiology. 2006;59:681-4.

[8] Hopewell S, Boutron I, Altman DG, Ravaud P. Deficiencies in the publication and reporting of the results of systematic reviews presented at scientific medical conferences. Journal of clinical epidemiology. 2015.

[9] Schulte TL, Huck K, Osada N, Trost M, Lange T, Schmidt C, et al. Publication rate of abstracts presented at the Annual Congress of the Spine Society of Europe (years 2000-2003). European spine journal : official publication of the European Spine Society, the European Spinal Deformity Society, and the European Section of the Cervical Spine Research Society. 2012;21:2105-12.

[10] Mihok P, Worley S, Hassaballa M, Punwar S, Porteous A, Murray J. BASK presentations: progress to journal publication. Orthopedics. 2013;36:e1269-71.

[11] Yalcinkaya M, Bagatur E. Fate of abstracts presented at a National Turkish Orthopedics and Traumatology Congress: publication rates and consistency of abstracts compared with their subsequent full-text publications. Acta orthopaedica et traumatologica turcica. 2013;47:223-30.

[12] Ohtori S, Kubota G, Inage K, Yamauchi K, Orita S, Suzuki M, et al. English publication rate of 3,205 abstracts presented at the Annual Meeting of the Japanese Orthopaedic Association and 
the Annual Research Meeting of the Japanese Orthopaedic Association. Journal of orthopaedic science : official journal of the Japanese Orthopaedic Association. 2013;18:1031-6.

[13] Scherer RW, Langenberg P, von Elm E. Full publication of results initially presented in abstracts. The Cochrane database of systematic reviews. 2007:MR000005.

[14] von Elm E, Costanza MC, Walder B, Tramer MR. More insight into the fate of biomedical meeting abstracts: a systematic review. BMC medical research methodology. 2003;3:12.

[15] Livas C, Pandis N, Ren Y. Full-text publication of abstracts presented at European Orthodontic Society congresses. European journal of orthodontics. 2014;36:569-75.

[16] Lee DJ, Yuan JCC, Prasad S, Barao VAR, Shyamsunder N, Sukotjo C. Analysis of Abstracts Presented at the Prosthodontic Research Section of IADR General Sessions 2004-2005: Demographics, Publication Rates, and Factors Contributing to Publication. Journal of Prosthodontics. 2012;21:225-31.

[17] Dahllof G, Wondimu B, Maniere MC. Subsequent publication of abstracts presented at the International Association of Paediatric Dentistry meetings. International journal of paediatric dentistry / the British Paedodontic Society [and] the International Association of Dentistry for Children. 2008;18:91-7.

[18] Moar K, Butterworth S. If you present will you publish? An analysis of abstracts at the Craniofacial Society of Great Britain and Ireland conferences 2000-2009. 6 ed. United States: American Cleft Palate Craniofacial Assocition (1504 East Franklin St. Suite 102, Chapel Hill NC 27514, United States); 2013. p. 713-6.

[19] Galang MT, Yuan JC, Lee DJ, Barao VA, Shyamsunder N, Sukotjo C. Factors influencing publication rates of abstracts presented at the ADEA annual session \& exhibition. Journal of dental education. 2011;75:549-56.

[20] Collier JM, Vig N, Hammond D. Publish or perish? A survey of abstracts accepted for meetings of the British Association of Oral and Maxillofacial Surgeons, and subsequently published. The British journal of oral \& maxillofacial surgery. 2010;48:540-3.

[21] Jara-Tracchia L, Aromando RF, Itoiz ME. Publication: Presentation rate in the Latin American region of the International Association for Dental Research. Acta odontologica latinoamericana : AOL. 2010;23:150-2.

[22] Bergoli CD, Amaral M, da Rosa RA, Ardenghi TM. Subsequent publication of abstracts presented at the Brazilian Society of Oral Research Meeting. IJD International Journal of Dentistry. 2011;10:200-3.

[23] Spencer ME, Preston C, Harrison JE. British Orthodontic Society, UTG session abstracts Publication bias of dental clinical trials. Journal of orthodontics. 2007;34:50.

[24] Chalmers I, Adams M, Dickersin K, Hetherington J, Tarnow-Mordi W, Meinert C, et al. A 
cohort study of summary reports of controlled trials. Jama. 1990;263:1401-5.

[25] Song F, Parekh-Bhurke S, Hooper L, Loke YK, Ryder JJ, Sutton AJ, et al. Extent of publication bias in different categories of research cohorts: a meta-analysis of empirical studies. BMC medical research methodology. 2009;9:79.

[26] Stroup DF, Berlin JA, Morton SC, Olkin I, Williamson GD, Rennie D, et al. Meta-analysis of observational studies in epidemiology: a proposal for reporting. Meta-analysis Of Observational Studies in Epidemiology (MOOSE) group. Jama. 2000;283:2008-12.

[27] Liberati A, Altman DG, Tetzlaff J, Mulrow C, Gotzsche PC, loannidis JP, et al. The PRISMA statement for reporting systematic reviews and meta-analyses of studies that evaluate health care interventions: explanation and elaboration. Plos Med. 2009;6:e1000100.

[28] Nyaga VN, Arbyn M, Aerts M. Metaprop: a Stata command to perform meta-analysis of binomial data. Archives of Public Health. 2014;72:39.

[29] DerSimonian R, Laird N. Meta-analysis in clinical trials. Controlled clinical trials. 1986;7:177-88.

[30] Egger M, Davey Smith G, Schneider M, Minder C. Bias in meta-analysis detected by a simple, graphical test. Bmj. 1997;315:629-34.

[31] Tanner - Smith EE, Tipton E. Robust variance estimation with dependent effect sizes: practical considerations including a software tutorial in Stata and SPSS. Research Synthesis Methods. 2014;5:13-30.

[32] Tipton E. Small sample adjustments for robust variance estimation with meta-regression. Psychological methods. 2014.

[33] Corry AM. A survey of the publication history of randomly selected IADR/AADR abstracts presented in 1983 and 1984. Journal of dental research. 1990;69:1453-5.

[34] Collet AM, Piloni MJ, Keszler A. Scientific presentations and their publication. Experience over a 10-year period in the Argentine Division of the I.A.D.R. Acta odontologica latinoamericana : AOL. 1993;7:39-46.

[35] Collet AM, Piloni MJ, Keszler A. Scientific presentations and publications on odontological research in Argentina. Acta odontologica latinoamericana : AOL. 1997;10:63-9.

[36] Bagheri SC, Lenox N, Verschueren DS, Holmgren E, Kademani D, Bell RB, et al. Abstracts from the American Association Of Oral And Maxillofacial Surgeons annual scientific meeting: proportion published and time to publication. Journal of oral and maxillofacial surgery : official journal of the American Association of Oral and Maxillofacial Surgeons. 2005;63:838-40.

[37] Scholey JM, Harrison JE. Delay and failure to publish dental research. Evidence-based dentistry. 2005;6:58-61.

[38] Leles CR, Rocha SS, Simões PA, Compagnoni MA. Publication rate of abstracts presented at a 
dental scientific meeting. Revista de Odontologia da UNESP. 2006;35:141-7.

[39] Zheng Y-n, Liu T, Gu Z-y. Investigation of changes of articles on China national academic stomatological conferences in last two decades. Stomatology. 2007;12:012.

[40] Malicki M, Marusic A, Consortium O. Is there a solution to publication bias? Researchers call for changes in dissemination of clinical research results. Journal of clinical epidemiology. 2014;67:1103-10.

[41] Chalmers I, Glasziou P, Godlee F. All trials must be registered and the results published. Bmj. 2013;346:f105.

[42] Scholey JM, Harrison JE. Publication bias: raising awareness of a potential problem in dental research. British dental journal. 2003;194:235-7.

[43] Weber EJ, Callaham ML, Wears RL, Barton C, Young G. Unpublished research from a medical specialty meeting: why investigators fail to publish. Jama. 1998;280:257-9.

[44] Scherer RW, Ugarte-Gil C, Schmucker C, Meerpohl JJ. Authors report lack of time as main reason for unpublished research presented at biomedical conferences: a systematic review. Journal of clinical epidemiology. 2015.

[45] Dickersin K. The existence of publication bias and risk factors for its occurrence. Jama. 1990;263:1385-9.

[46] Stewart SB, Oeppen RS, Cascarini L, Brennan PA. Educational article: what gets accepted for presentation?--a study of submitted abstracts for the 2009 BAOMS Conference. The British journal of oral \& maxillofacial surgery. 2010;48:297-300.

[47] Krzyzanowska MK, Pintilie M, Tannock IF. Factors associated with failure to publish large randomized trials presented at an oncology meeting. Jama. 2003;290:495-501.

[48] Rezaeian M. Rejected epidemiologic manuscripts: food for thought. Journal of clinical epidemiology. 2015;68:596.

[49] Yuan HF, Xu WD, Hu HY. Young Chinese doctors and the pressure of publication. Lancet. 2013;381:e4.

[50] Zhang Z, Winston GP, Zhao HT, Oei EH, Ai Q, Loffroy R, et al. Focus on China: should clinicians engage in research? and lessons from other countries. Quantitative imaging in medicine and surgery. 2014;4:413-25.

[51] Brazzelli M, Lewis SC, Deeks JJ, Sandercock PA. No evidence of bias in the process of publication of diagnostic accuracy studies in stroke submitted as abstracts. Journal of clinical epidemiology. 2009;62:425-30.

[52] Hopewell S, Clarke M, Moher D, Wager E, Middleton P, Altman DG, et al. CONSORT for reporting randomized controlled trials in journal and conference abstracts: explanation and elaboration. Plos Med. 2008;5:e20. 
Table 1. Criteria for the quality assessment of included studies.

\begin{tabular}{|c|c|c|}
\hline Components & No. & Scoring Items ${ }^{a}$ \\
\hline \multirow[t]{2}{*}{$\begin{array}{l}\text { Sampling } \\
\text { methods }\end{array}$} & $1^{b}$ & $\begin{array}{l}\text { Both abstracts presented in oral and poster sessions } \\
\text { were included. }\end{array}$ \\
\hline & 2 & $\begin{array}{l}\text { The sample size was not smaller than the median (117 } \\
\text { abstracts). }\end{array}$ \\
\hline $\begin{array}{l}\text { Length of } \\
\text { follow-up }\end{array}$ & 3 & $\begin{array}{l}\text { The length of follow-up was not shorter than the median } \\
\text { (76 months). }\end{array}$ \\
\hline $\begin{array}{l}\text { Ascertainment } \\
\text { of full }\end{array}$ & 4 & $\begin{array}{l}\text { Multiple }(\geq 2) \text { databases were used to search for full } \\
\text { publications. }\end{array}$ \\
\hline \multirow[t]{4}{*}{ publication } & 5 & $\begin{array}{l}\text { When no corresponding full publications could be found, } \\
\text { the original abstract authors were contacted for } \\
\text { confirmation of no full publication. }\end{array}$ \\
\hline & 6 & $\begin{array}{l}\text { Full papers published before their corresponding } \\
\text { conference dates were checked and included. }\end{array}$ \\
\hline & 7 & $\begin{array}{l}\text { Detailed criteria for matching the abstract and relevant } \\
\text { full publications were used. }\end{array}$ \\
\hline & 8 & $\begin{array}{l}\text { No language restrictions were applied during literature } \\
\text { searches and study selection. }\end{array}$ \\
\hline
\end{tabular}

\footnotetext{
a For each quality item, a score of " 1 " was given when it was fulfilled, a score of " 0 " when it was not.

${ }^{b}$ When no information regarding the presentation types of included abstracts was found, and the authors did mention that "all abstracts presented at the conference were included", we assumed that this quality item was met.
} 
Table 2. Characteristics of included subsamples ( 42 for FPR of all abstracts, 3 for FPR of trial abstracts only). ${ }^{\text {a }}$

\begin{tabular}{|c|c|c|c|c|c|c|c|c|c|c|}
\hline No. & $\begin{array}{l}\text { First author } \\
\text { (Publication year) }\end{array}$ & Conference $^{b}$ & $\begin{array}{l}\text { Loca- } \\
\text { tion }\end{array}$ & Subject ${ }^{d}$ & Level & $\begin{array}{l}\text { No. of } \\
\text { abstracts }\end{array}$ & $\begin{array}{l}\text { No. of full } \\
\text { papers }\end{array}$ & FPR & $\begin{array}{l}\text { Trials } \\
\text { only }^{e}\end{array}$ & $\begin{array}{l}\text { Quality Score } \\
\text { (criteria met }{ }^{f} \text { ) }\end{array}$ \\
\hline 1 & Corry (1990) & 1983 IADR/AADR & N.A. & Dentistry & International & 125 & 27 & $21.60 \%$ & No & $5(1,2,4,7,8)$ \\
\hline 2 & Corry (1990) & 1984 IADR/AADR & N.A. & Dentistry & International & 150 & 36 & $24.00 \%$ & No & $5(1,2,4,7,8)$ \\
\hline 3 & Collet (1993) & 1980 IADR Argentine Division & S.A. & Dentistry & National & 66 & 0 & $0.00 \%$ & No & $4(1,3,4,8)$ \\
\hline 4 & Collet (1993) & 1981 IADR Argentine Division & S.A. & Dentistry & National & 86 & 1 & $1.16 \%$ & No & $4(1,3,4,8)$ \\
\hline 5 & Collet (1993) & 1982 IADR Argentine Division & S.A. & Dentistry & National & 112 & 2 & $1.79 \%$ & No & $4(1,3,4,8)$ \\
\hline 6 & Collet (1993) & 1983 IADR Argentine Division & S.A. & Dentistry & National & 92 & 15 & $16.30 \%$ & No & $4(1,3,4,8)$ \\
\hline 7 & Collet (1993) & 1984 IADR Argentine Division & S.A. & Dentistry & National & 88 & 19 & $21.59 \%$ & No & $3(1,4,8)$ \\
\hline 8 & Collet (1993) & 1985 IADR Argentine Division & S.A. & Dentistry & National & 67 & 20 & $29.85 \%$ & No & $3(1,4,8)$ \\
\hline 9 & Collet (1993) & 1986 IADR Argentine Division & S.A. & Dentistry & National & 73 & 12 & $16.44 \%$ & No & $3(1,4,8)$ \\
\hline 10 & Collet (1997) & 1990 IADR Argentine Division & S.A. & Dentistry & National & 65 & 13 & $20.00 \%$ & No & $2(1,8)$ \\
\hline 11 & Collet (1997) & 1991 IADR Argentine Division & S.A. & Dentistry & National & 101 & 11 & $10.89 \%$ & No & $2(1,8)$ \\
\hline 12 & Bagheri (2005) * & $\begin{array}{l}\text { 1997, } 1998 \text { \& } 1999 \text { AAOMS } \\
\text { Annual Scientific Meetings }\end{array}$ & N.A. & OMFS & National & 446 & 155 & $34.75 \%$ & No & $3(1,2,8)$ \\
\hline 13 & Scholey (2005) & 1993 IADR & N.A. & Dentistry & International & 256 & 116 & $45.31 \%$ & No & $5(1,2,6,7,8)$ \\
\hline 14 & Scholey (2005) & 1993 ORCA Congress & Europe & Cariology & Continental & 115 & 58 & $50.43 \%$ & No & $5(1,2,6,7,8)$ \\
\hline 15 & Scholey (2005) & 1993 EOS Congress & Europe & Orthodontics & Continental & 175 & 78 & $44.57 \%$ & No & $5(1,2,6,7,8)$ \\
\hline 16 & Leles (2006) & $\begin{array}{l}1999 \text { Brazilian Oral Research } \\
\text { Society Annual Meeting }\end{array}$ & S.A. & Dentistry & National & 775 & 116 & $14.97 \%$ & No & $4(1,2,6,8)$ \\
\hline 17 & Zheng (2007) & $\begin{array}{l}1988 \text { China National Academic } \\
\text { Stomatological Conference }\end{array}$ & Asia & Dentistry & National & 310 & 196 & $63.23 \%$ & No & $5(1,2,3,4,6)$ \\
\hline 18 & Zheng (2007) & $\begin{array}{l}2001 \text { China National Academic } \\
\text { Stomatological Conference }\end{array}$ & Asia & Dentistry & National & 213 & 134 & $62.91 \%$ & No & $4(1,2,4,6)$ \\
\hline 19 & Dahllöf (2008) & 1999 IAPD Congress & Europe & PD & International & 385 & 108 & $28.05 \%$ & No & $5(1,2,3,6,8)$ \\
\hline 20 & Dahllöf (2008) & 2001 IAPD Congress & Europe & PD & International & 386 & 96 & $24.87 \%$ & No & $4(1,2,6,8)$ \\
\hline 21 & $\begin{array}{l}\text { Jara-Tracchia (2010) } \\
*\end{array}$ & $\begin{array}{l}2002 \text { \& } 2003 \text { IADR Argentine } \\
\text { Division }\end{array}$ & S.A. & Dentistry & National & 416 & 119 & $28.61 \%$ & No & $4(1,2,3,8)$ \\
\hline
\end{tabular}




\begin{tabular}{|c|c|c|c|c|c|c|c|c|c|c|}
\hline 22 & $\begin{array}{l}\text { Jara-Tracchia (2010) } \\
*\end{array}$ & $\begin{array}{l}2002 \text { \& } 2003 \text { IADR Brazil } \\
\text { Division }\end{array}$ & S.A. & Dentistry & National & 3288 & 997 & $30.32 \%$ & No & $4(1,2,3,8)$ \\
\hline 23 & $\begin{array}{l}\text { Jara-Tracchia (2010) } \\
*\end{array}$ & $\begin{array}{l}2002 \text { \& } 2003 \text { IADR Chile } \\
\text { Division }\end{array}$ & S.A. & Dentistry & National & 104 & 17 & $16.35 \%$ & No & $3(1,3,8)$ \\
\hline 24 & $\begin{array}{l}\text { Jara-Tracchia (2010) } \\
*\end{array}$ & $\begin{array}{l}2002 \text { \& } 2003 \text { IADR Peru } \\
\text { Division }\end{array}$ & S.A. & Dentistry & National & 67 & 1 & $1.49 \%$ & No & $3(1,3,8)$ \\
\hline 25 & $\begin{array}{l}\text { Jara-Tracchia (2010) } \\
*\end{array}$ & $\begin{array}{l}2002 \text { \& } 2005 \text { IADR Venezuela } \\
\text { Division }\end{array}$ & S.A. & Dentistry & National & 262 & 22 & $8.40 \%$ & No & $3(1,2,8)$ \\
\hline 26 & Collier (2010) & 2002 BAOMS annual meeting & Europe & OMFS & National & 112 & 26 & $23.21 \%$ & No & $3(1,6,8)$ \\
\hline 27 & Collier (2010) & 2003 BAOMS annual meeting & Europe & OMFS & National & 119 & 29 & $24.37 \%$ & No & $4(1,2,6,8)$ \\
\hline 28 & Bergoli (2011) & $\begin{array}{l}2001 \text { Brazilian Oral Research } \\
\text { Society Annual Meeting }\end{array}$ & S.A. & Dentistry & National & 140 & 37 & $26.43 \%$ & No & $7(1,2,3,4,6,7,8)$ \\
\hline 29 & Galang (2011) & 2002 ADEA annual session & N.A. & $\mathrm{DE}$ & National & 213 & 41 & $19.25 \%$ & No & $5(2,3,6,7,8)$ \\
\hline 30 & Galang (2011) & 2003 ADEA annual session & N.A. & $\mathrm{DE}$ & National & 158 & 30 & $18.99 \%$ & No & $4(2,6,7,8)$ \\
\hline 31 & Lee (2012) & 2004 IADR Prostho. Section & N.A. & Prostho. & International & 181 & 64 & $35.36 \%$ & No & $3(1,2,3)$ \\
\hline 32 & Lee (2012) & 2005 IADR Prostho. Section & N.A. & Prostho. & International & 165 & 64 & $38.79 \%$ & No & $2(1,2)$ \\
\hline 33 & Moar (2013) & 2000 CFSGBI Conference & Europe & Cleft research & National & 24 & 9 & $37.50 \%$ & No & $3(3,7,8)$ \\
\hline 34 & Moar (2013) & 2001 CFSGBI Conference & Europe & Cleft research & National & 28 & 2 & $7.14 \%$ & No & $3(3,7,8)$ \\
\hline 35 & Moar (2013) & 2002 CFSGBI Conference & Europe & Cleft research & National & 32 & 4 & $12.50 \%$ & No & $3(3,7,8)$ \\
\hline 36 & Moar (2013) & 2003 CFSGBI Conference & Europe & Cleft research & National & 38 & 14 & $36.84 \%$ & No & $3(3,7,8)$ \\
\hline 37 & Moar (2013) & 2004 CFSGBI Conference & Europe & Cleft research & National & 34 & 7 & $20.59 \%$ & No & $3(3,7,8)$ \\
\hline 38 & Moar (2013) & 2005 CFSGBI Conference & Europe & Cleft research & National & 36 & 4 & $11.11 \%$ & No & $3(3,7,8)$ \\
\hline 39 & Moar (2013) & 2006 CFSGBI Conference & Europe & Cleft research & National & 31 & 2 & $6.45 \%$ & No & $2(7,8)$ \\
\hline 40 & Moar (2013) & 2007 CFSGBI Conference & Europe & Cleft research & National & 33 & 10 & $30.30 \%$ & No & $2(7,8)$ \\
\hline 41 & Livas (2014) & 2006 EOS Congress & Europe & Orthodontics & Continental & 333 & 168 & $50.45 \%$ & No & $7(1,2,3,4,6,7,8)$ \\
\hline 42 & Livas (2014) & 2007 EOS Congress & Europe & Orthodontics & Continental & 257 & 140 & $54.47 \%$ & No & $6(1,2,4,6,7,8)$ \\
\hline 43 & Spencer (2007) & 2000 IADR & N.A. & Dentistry & International & 170 & 64 & $37.65 \%$ & Yes & $4(1,2,7,8)$ \\
\hline 44 & Spencer (2007) & 2000 ORCA Congress & Europe & Cariology & Continental & 21 & 10 & $47.62 \%$ & Yes & $3(1,7,8)$ \\
\hline 45 & Spencer (2007) & 2000 EOS Congress & Europe & Orthodontics & Continental & 17 & 5 & $29.41 \%$ & Yes & $3(1,7,8)$ \\
\hline
\end{tabular}


${ }^{a}$ Adjacent rows in the same background color are subsamples from the same study.

b IADR, International Association for Dental Research; AADR, American Association for Dental Research; AAOMS, American Association of Oral and Maxillofacial Surgeons; ORCA, European Organisation for Caries Research; EOS, European Orthodontic Society; IAPD, International Association of Paediatric Dentistry; BAOMS, British Association of Oral and Maxillofacial Surgeons; ADEA, American Dental Education Association; CFSGBI, Craniofacial Society of Great Britain and Ireland.

${ }^{c}$ N.A., North America; S.A., South America.

d OMFS, Oral and Maxillofacial Surgery; PD, Pediatric Dentistry; DE, Dental Education; Prostho., Prosthodontics.

e Whether the study included only abstracts describing clinical trials.

f $1=$ included both oral and poster abstracts; $2=a$ sample size not smaller than the median (117 abstracts); $3=a$ follow-up length not shorter than the median (76 months); 4=more than 1 database was searched, $5=$ author contact for confirmation of no full publication; $6=$ full papers published before conference were checked and included; $7=$ detailed matching criteria; $8=$ no language restrictions.

* Only combined FPR reported due to unavailability of separate FPR for each conference. 
Table 3. Results of meta-analyses regarding the association between FPR and abstract characteristics.

\begin{tabular}{|c|c|c|c|c|c|c|}
\hline \multirow[b]{2}{*}{ Characteristic } & \multirow{2}{*}{$\begin{array}{l}\text { Number } \\
\text { of studies }\end{array}$} & \multicolumn{2}{|c|}{ Risk ratio } & \multicolumn{2}{|c|}{ Heterogeneity } & \multirow{2}{*}{$\begin{array}{c}\text { Significance } \\
\left(\mathbf{P}_{\text {effect }}\right)\end{array}$} \\
\hline & & Pooled estimate & $95 \% \mathrm{Cl}$ & $I^{2}$ & P value & \\
\hline Positive vs. Negative & 2 & 0.80 & 0.53 to 1.21 & $0.0 \%$ & 0.620 & 0.294 \\
\hline Statistically significant vs. & 3 & 0.87 & 0.65 to 1.15 & $68.5 \%$ & 0.042 & 0.326 \\
\hline \multicolumn{7}{|l|}{ Nonsignificant } \\
\hline With vs. Without statistical tests & 3 & 2.02 & 1.54 to 2.65 & $0.0 \%$ & 0.374 & $<0.001$ \\
\hline Analytical vs. Descriptive statistics only & 2 & 1.44 & 0.59 to 3.53 & $88.3 \%$ & 0.003 & 0.424 \\
\hline Oral vs. Poster presentation & 5 & 1.51 & 1.29 to 1.76 & $58.4 \%$ & 0.047 & $<0.001$ \\
\hline Basic science vs. Clinical research & 4 & 1.49 & 1.01 to 2.22 & $86.5 \%$ & $<0.001$ & 0.047 \\
\hline Funded vs. Non-funded & 2 & 1.42 & 1.09 to 1.84 & $0.0 \%$ & 0.755 & 0.009 \\
\hline Europe vs. Other continents & 2 & 1.22 & 0.80 to 1.87 & $88.0 \%$ & 0.004 & 0.361 \\
\hline Asia vs. Other continents & 2 & 0.95 & 0.82 to 1.10 & $0.0 \%$ & 0.552 & 0.473 \\
\hline
\end{tabular}


Table 4. Univariable and multivariable meta-regression analyses on full publication rate.

\begin{tabular}{|c|c|c|c|c|c|c|c|c|}
\hline \multirow[b]{2}{*}{ Explanatory variable } & \multirow[b]{2}{*}{ Category/unit } & \multicolumn{4}{|c|}{ Univariable } & \multicolumn{3}{|c|}{ Multivariable $^{a}$} \\
\hline & & B (\%) & $95 \% \mathrm{Cl}(\%)$ & P value & $R^{2}(\%)$ & $\mathrm{B}(\%)$ & $95 \% \mathrm{Cl}(\%)$ & P value \\
\hline \multicolumn{9}{|l|}{ Conference characteristics } \\
\hline \multirow[t]{5}{*}{ Location } & & & & $<0.001$ & 43.23 & & & \\
\hline & North America & Reference & & & & Reference & & \\
\hline & Asia $^{\mathbf{b}}$ & 33.33 & $(13.52,53.13)$ & 0.002 & & 39.83 & $(23.58,56.08)$ & $<0.001$ \\
\hline & Europe & -0.68 & $(-11.74,10.39)$ & 0.902 & & -6.97 & $(-16.88,2.93)$ & 0.162 \\
\hline & South America & -14.73 & $(-25.60,-3.86)$ & 0.009 & & -7.30 & $(-17.80,3.20)$ & 0.167 \\
\hline \multirow[t]{4}{*}{ Level } & & & & $<0.001$ & 27.77 & & & \\
\hline & National & Reference & & & & Reference & & \\
\hline & Continental & 29.25 & $(14.20,44.31)$ & $<0.001$ & & 30.91 & $(16.84,44.98)$ & $<0.001$ \\
\hline & International & 10.36 & $(-1.44,22.16)$ & 0.084 & & 9.60 & $(-0.73,19.94)$ & 0.068 \\
\hline \multirow{8}{*}{ Subject } & Dentistry & Reference & & & & & & \\
\hline & Cariology & 28.58 & $(-3.09,60.25)$ & 0.075 & & & & \\
\hline & Cleft Research & -2.60 & $(-15.83,10.64)$ & 0.693 & & & & \\
\hline & Dental Education & -2.74 & $(-25.00,19.53)$ & 0.804 & & & & \\
\hline & OMFS & 5.71 & $(-13.00,24.41)$ & 0.539 & & & & \\
\hline & Orthodontics & 28.01 & $(9.37,46.66)$ & 0.004 & & & & \\
\hline & Paediatric Dentistry & 4.60 & $(-17.50,26.71)$ & 0.675 & & & & \\
\hline & Prosthodontics & 15.21 & $(-7.29,37.71)$ & 0.178 & & & & \\
\hline \multicolumn{9}{|l|}{ Methodological quality } \\
\hline Quality score & Per unit & 5.56 & $(1.72,9.41)$ & 0.006 & 16.21 & 0.46 & $(-2.59,3.52)$ & 0.760 \\
\hline
\end{tabular}

${ }^{\mathrm{a}}$ For the final multivariable meta-regression model, variable 'Subject' was excluded due to collinearity. Constant $=-7.65$, adjusted $\mathrm{R}^{2}=70.81 \%, \mathrm{P}<0.001$.

${ }^{b}$ For this category, only one study from China was included. 
Figure 1. Flow chart of study selection.

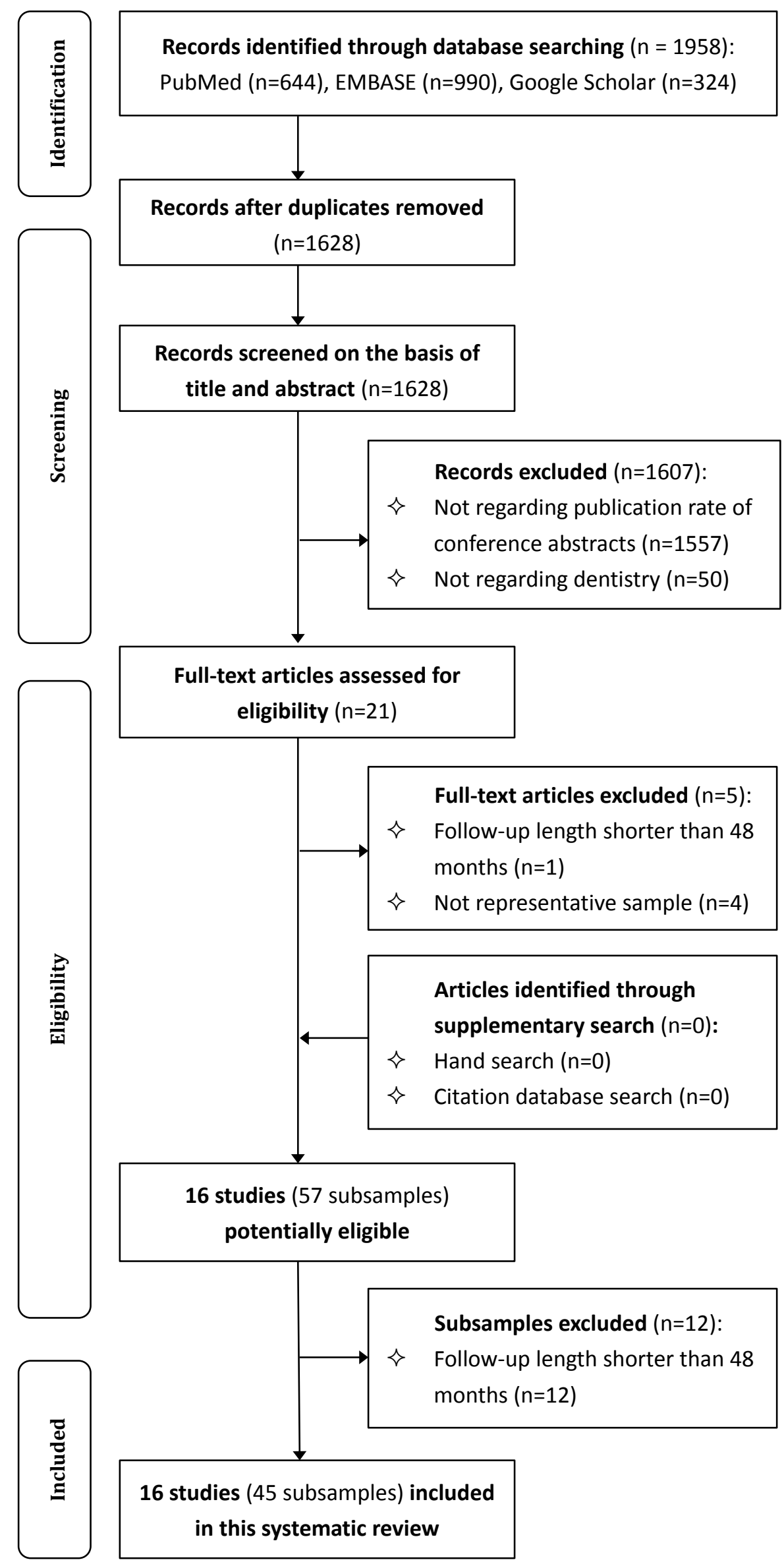


Figure 2. The forest plot for pooled overall FPR.

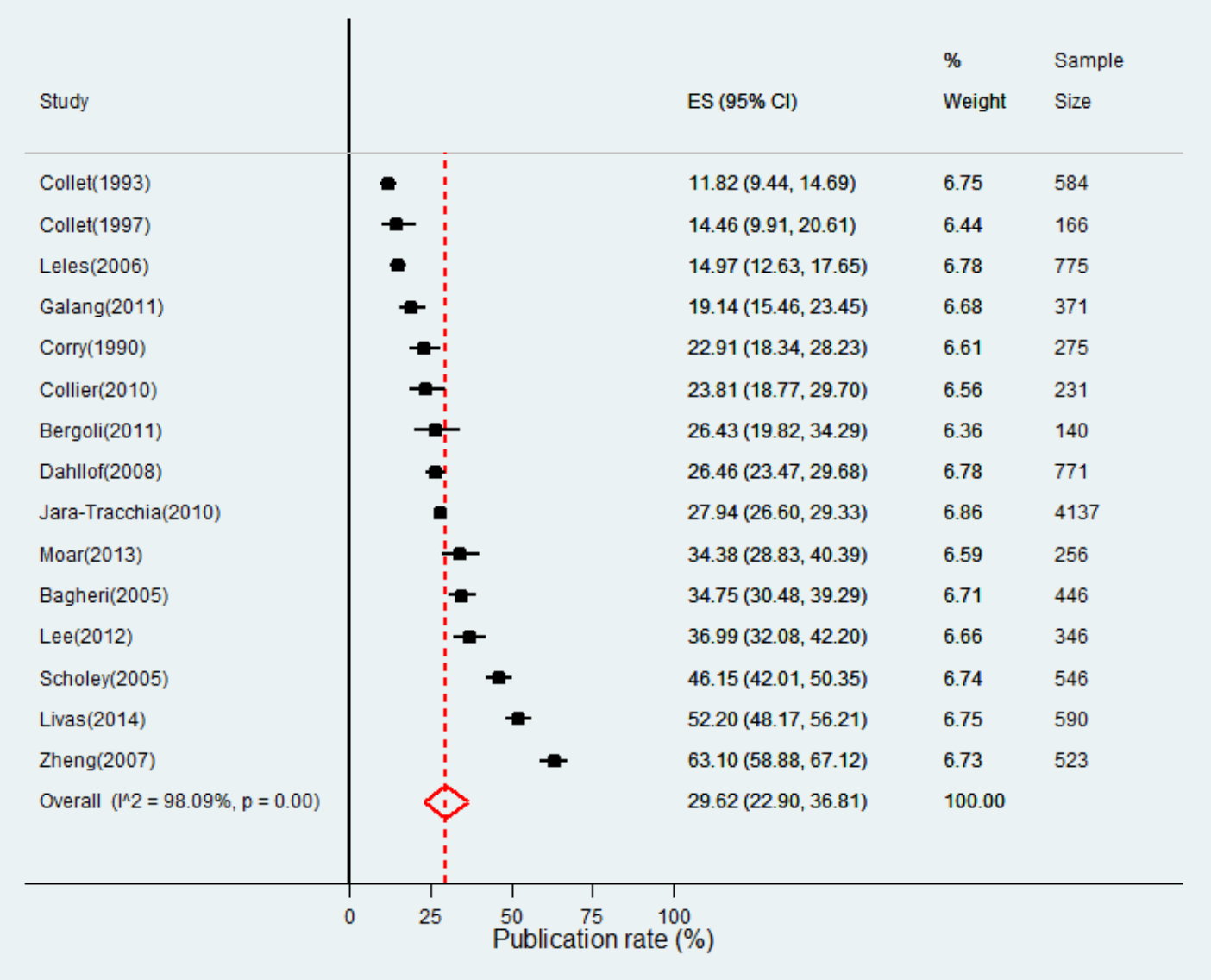




\section{Publication fate of abstracts presented at dental conferences:}

\section{A systematic review and meta-analysis}

\section{APPENDICES}

Appendix A. Search Strategy for Electronic Databases.

- MEDLINE via PubMed (1950 - 23 November 2014):

1. (publishing[MeSH Terms]) OR (periodicals as topic[MeSH Terms]) OR (posters as topic[MeSH Terms]) OR (abstracting and indexing as topic[MeSH Terms])

2. ((publication*[Title/Abstract] OR publish*[Title/Abstract] OR text*[Title/Abstract] OR paper*[Title/Abstract] OR article*[Title/Abstract])) AND (rate*[Title/Abstract] OR ratio*[Title/Abstract] OR proportion*[Title/Abstract] OR subsequent*[Title/Abstract] OR full[Title/Abstract] OR (time to)[Title/Abstract] OR delay[Title/Abstract]) OR full-text*[Title/Abstract] OR full-length[Title/Abstract]

3. 1 OR 2

4. dentistry[MeSH Terms]

5. dentist* OR dental OR (oral health) OR stomatolog* OR odontolog* OR (oral medicine) OR orthodont* OR periodont* OR endodont* OR prosthodont* OR (oral implantolog*) OR (oral surg*) OR (oral hygien*) OR gerodont* OR caries OR cariology OR maxillofacial OR orofacial OR cleft*

6. 4 OR 5

7. (congresses as topic[MeSH Terms]) OR (societies, dental[MeSH Terms])

8. (meeting*[Title/Abstract] OR conference*[Title/Abstract] OR congress*[Title/Abstract] OR session*[Title/Abstract])

9. 7 OR 8

10. 3 AND 6 AND 9 
- EMBASE via OVID (1974 - 23 November 2014):

1. publication.sh.

2. publishing.sh.

3. documentation.sh.

4. peer review.sh.

5. or/1-4

6. (publication\$ or publish\$ or text\$ or paper\$ or article).ti,ot,ab.

7. (rate\$ or ratio\$ or proportion\$ or subsequent\$ or full or "time to" or delay).ti,ot,ab.

8. 6 and 7

9. ("full-text" or "full-length").ti,ot,ab.

10. 5 or 8 or 9

11. dental research.sh.

12. dentistry.sh.

13. (dentist\$ or dental or "oral health" or stomatolog\$ or odontology\$ or "oral medicine" or orthodont\$ or periodont\$ or endodont\$ or prosthodont\$ or "oral implantology" or "oral implantologists" or "oral hygienists" or gerodont\$ or caries or cariology or maxillofacial or orofacial or cleft\$).ti,ot,ab.

14. or/11-13

15. medical society.sh

16. health care organization.sh

17. organization.sh

18. (meeting\$ or conference\$ or congress\$ or session\$).ti,ot,ab.

19. or/15-18

20. 10 and 14 and 19

- Google Scholar:

"publication rate" abstracts dental conference 
Appendix B. Imputation Methods for Unavailable Data.

1. End date of follow-up:

This date means the last date on which authors determined the publication fate of abstracts. It could be the last date on which authors carried out literature searches for full publications, or the end date of a time frame if the authors used any such restriction in their literature searches. This date was essential for the calculation of follow-up length (in months). For 3 included studies in which the year was known but the month was not, $1^{\text {st }}$ July of that year was used as a proxy date. For 2 studies in which both year and month were unknown, this date was imputed as 22 months before the final publication date of the study report. 22 months was the average time lag (median, 20 months) from end of follow-up to final publication, in all included subsamples that reported those two dates.

2. Conference date:

The exact date (month, year) of each conference was deemed as the starting point of follow-up, and was thus essential for the calculation of follow-up length. For 4 studies, the conference date (only month) could not be obtained from either the study reports or the Internet. We used $1^{\text {st }}$ July of the corresponding year as a proxy date.

Appendix C. Funnel Plot for the Pooled Overall FPR.

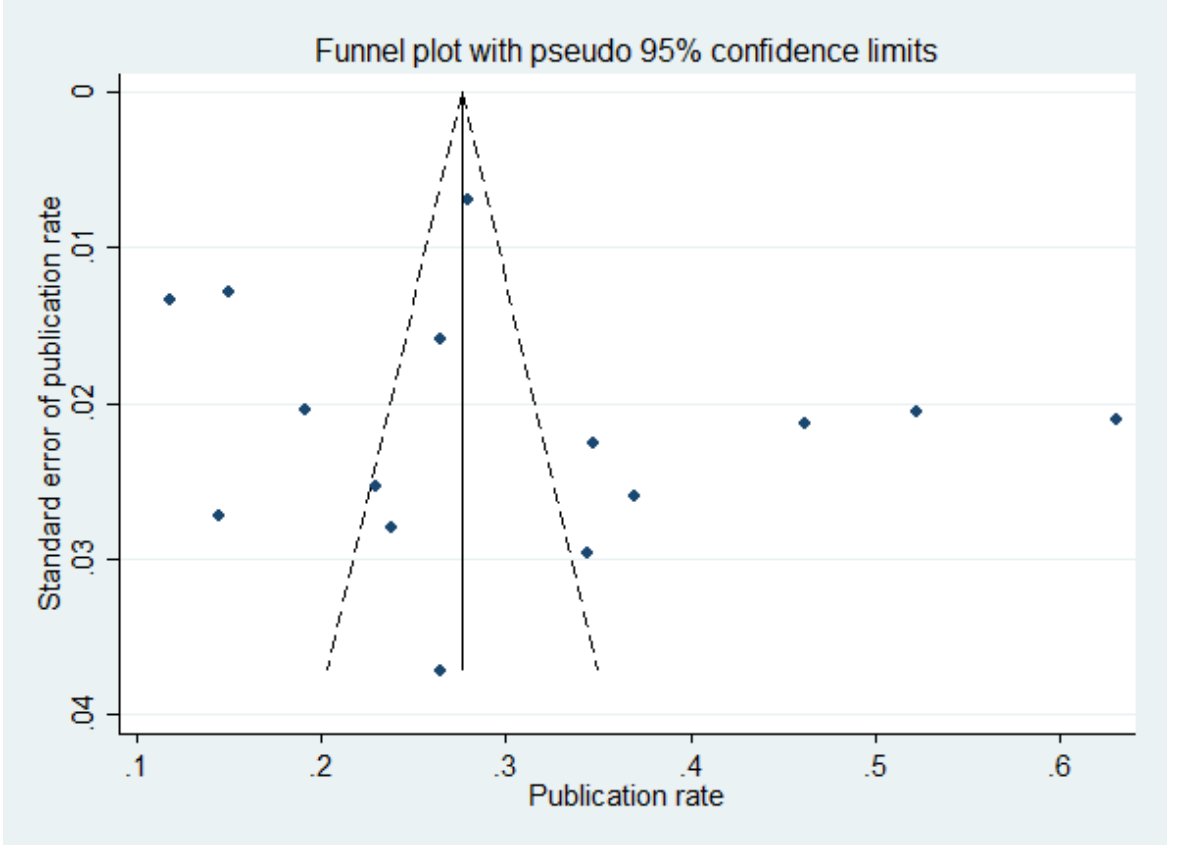


Appendix D. Forest plots showing the association between FPR and (1) positive results; (2) statistical significance; (3) presence of statistical tests; (4) type of statistics used; (5) type of presentation; (6) type of research; (7) financial support; (8) and (9) geographic origin of authors.

(1).

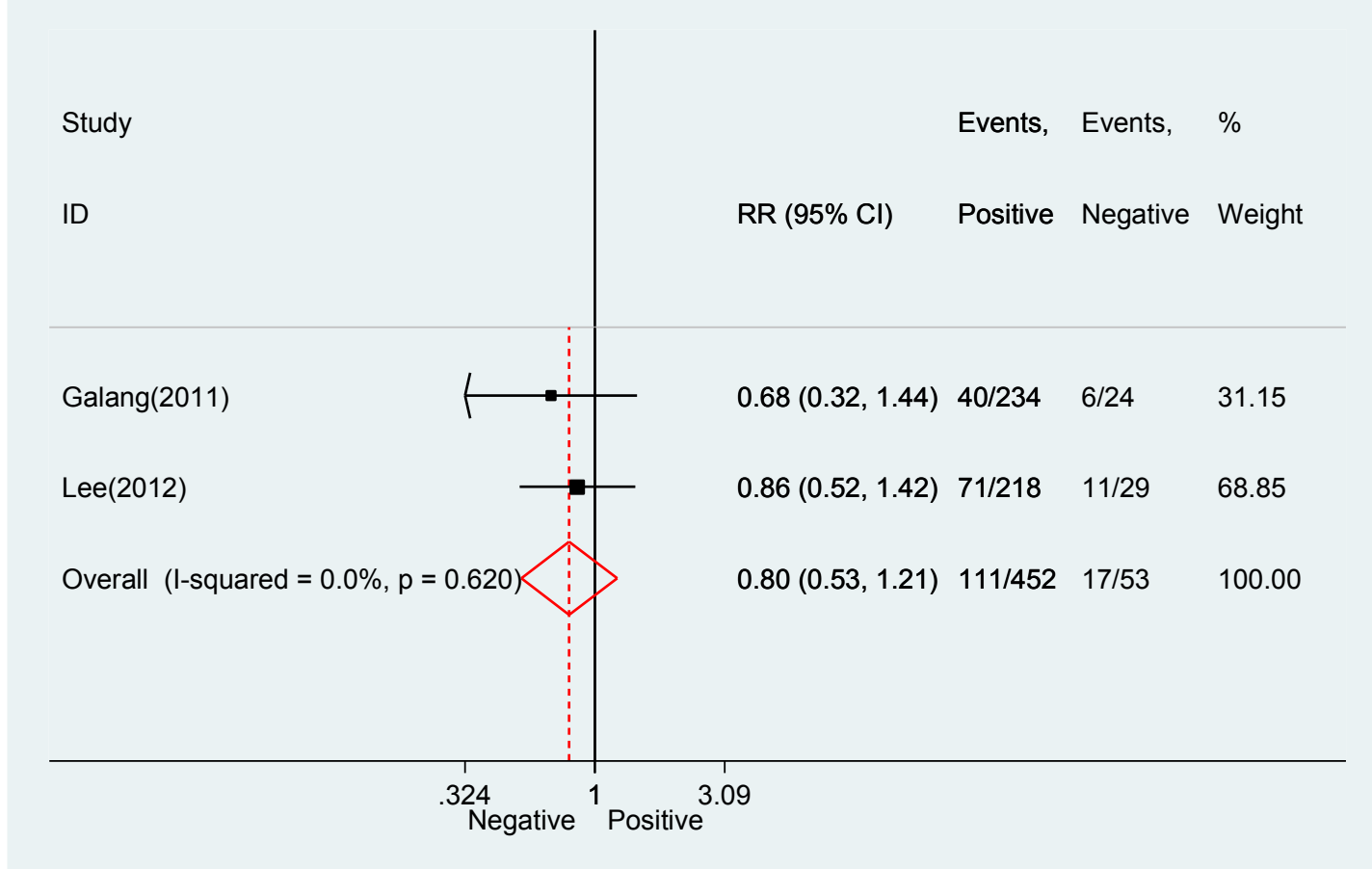

(2).

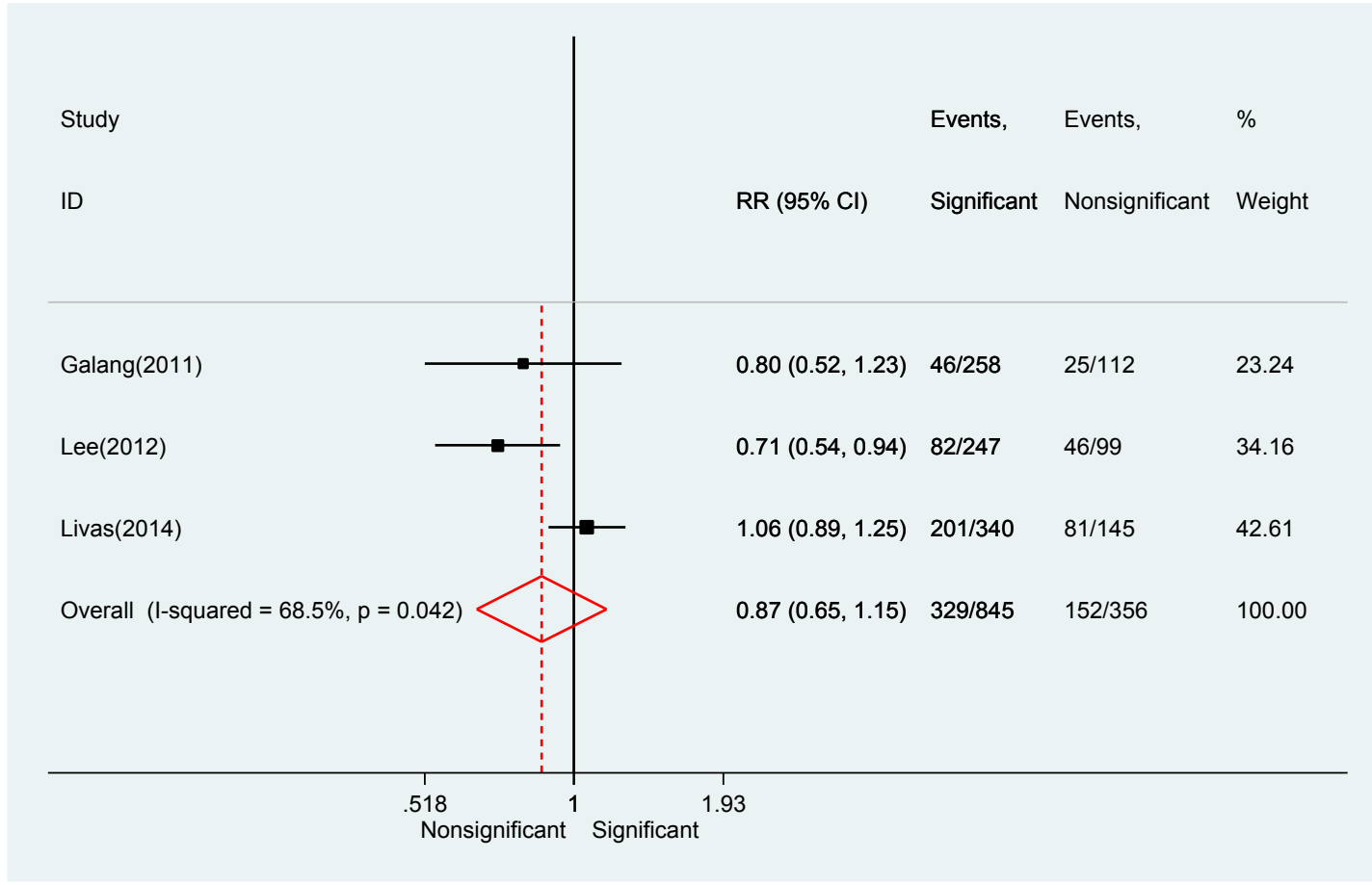


(3).

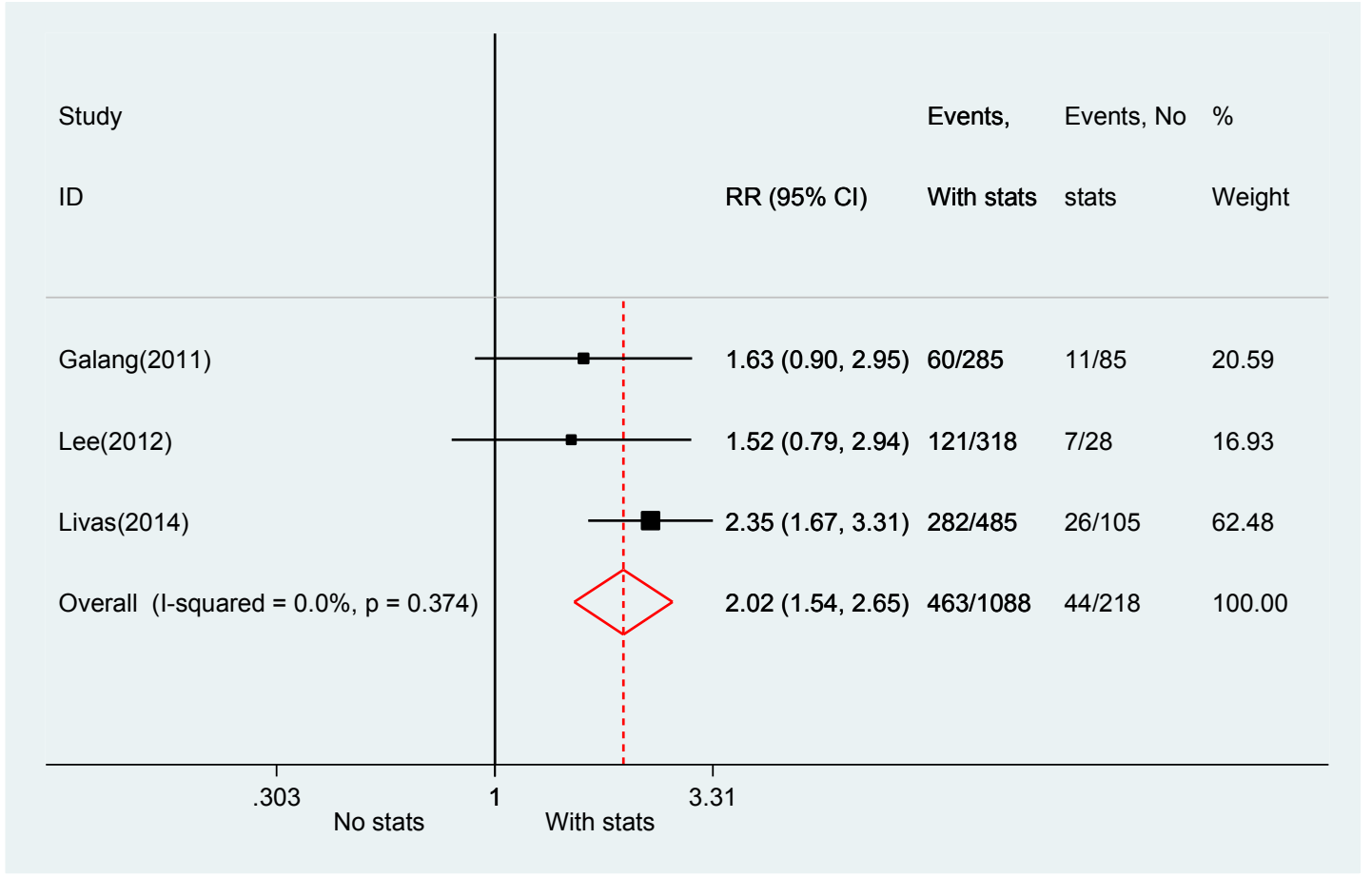

(4).

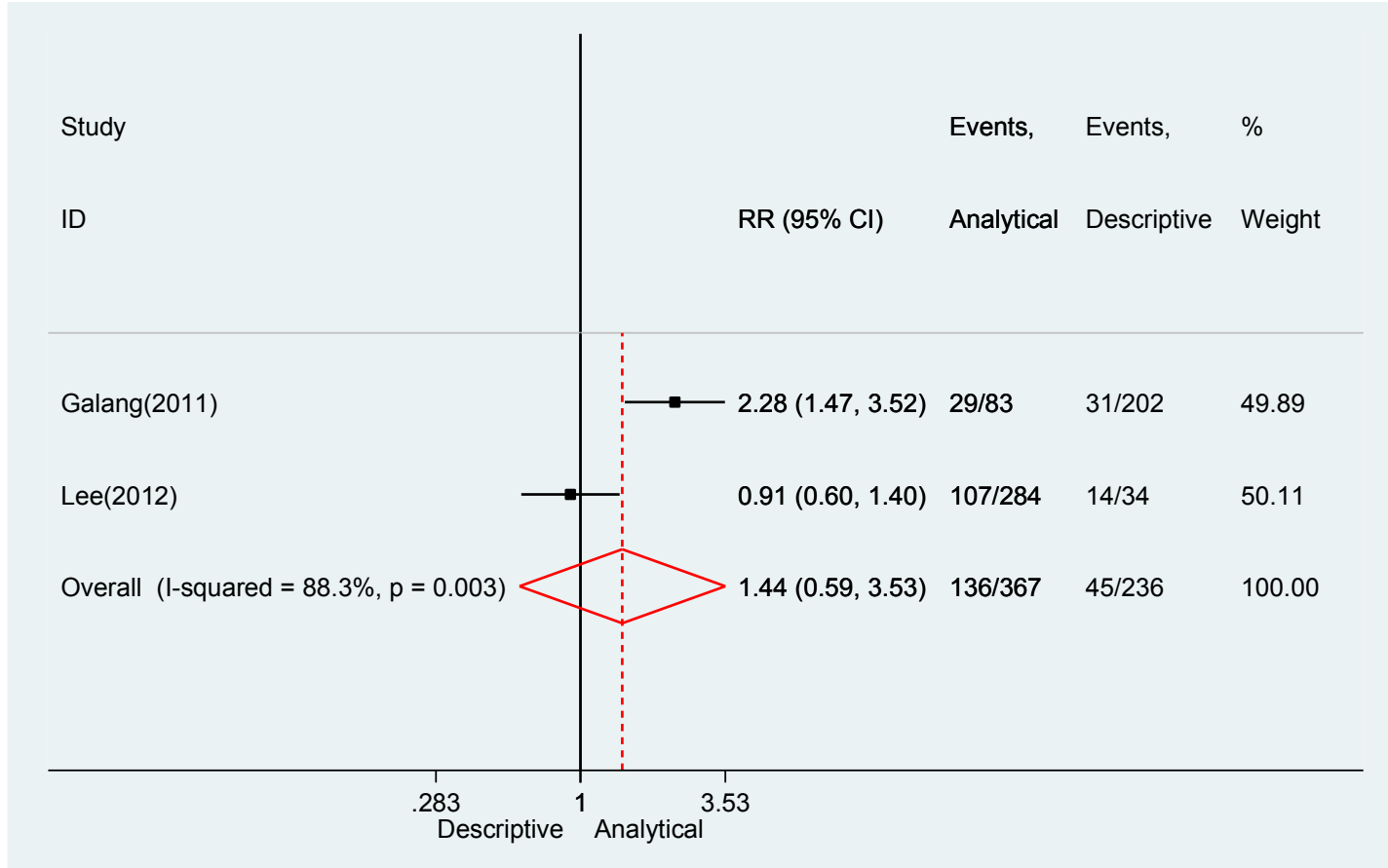


(5).

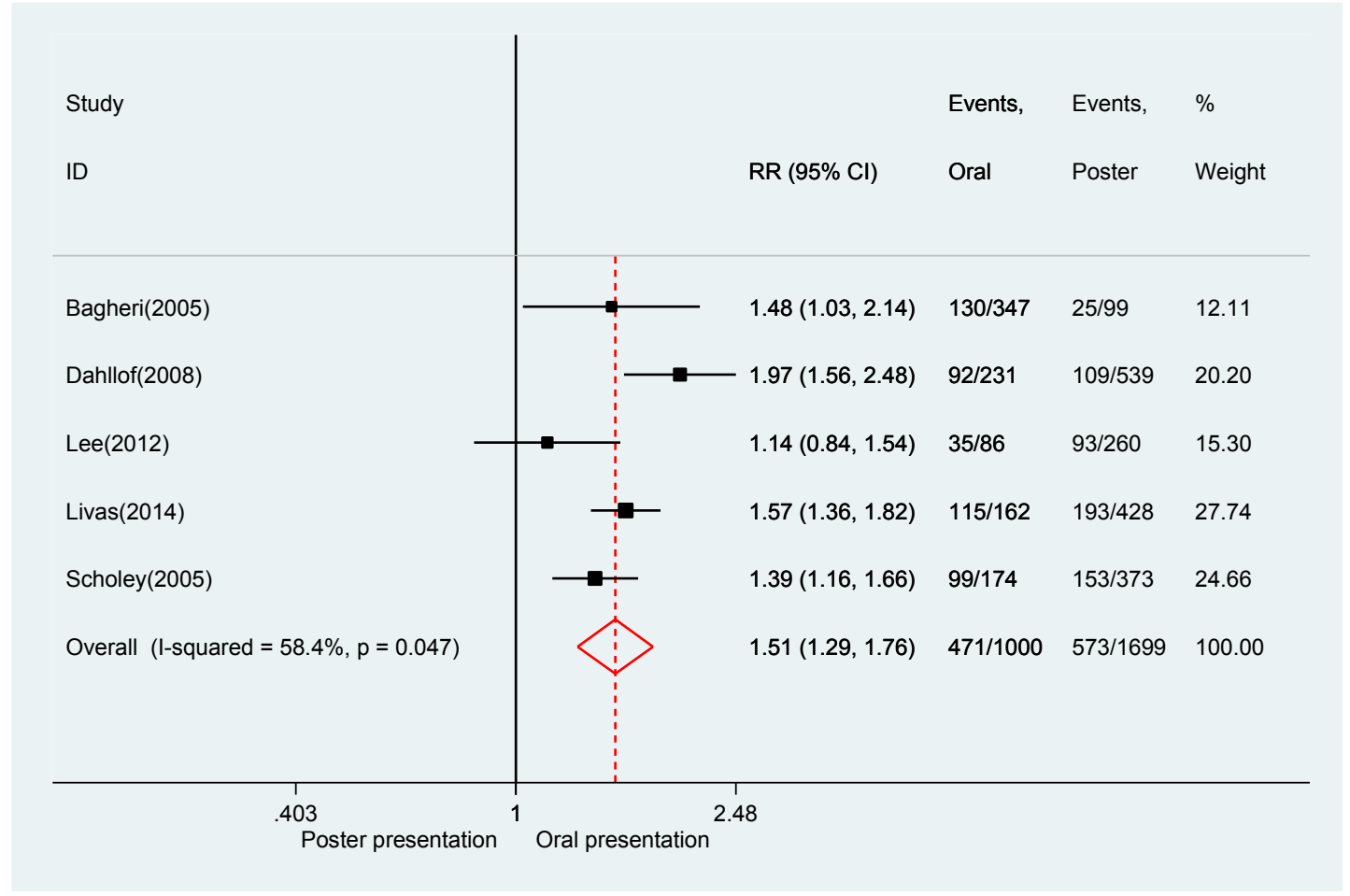

(6).

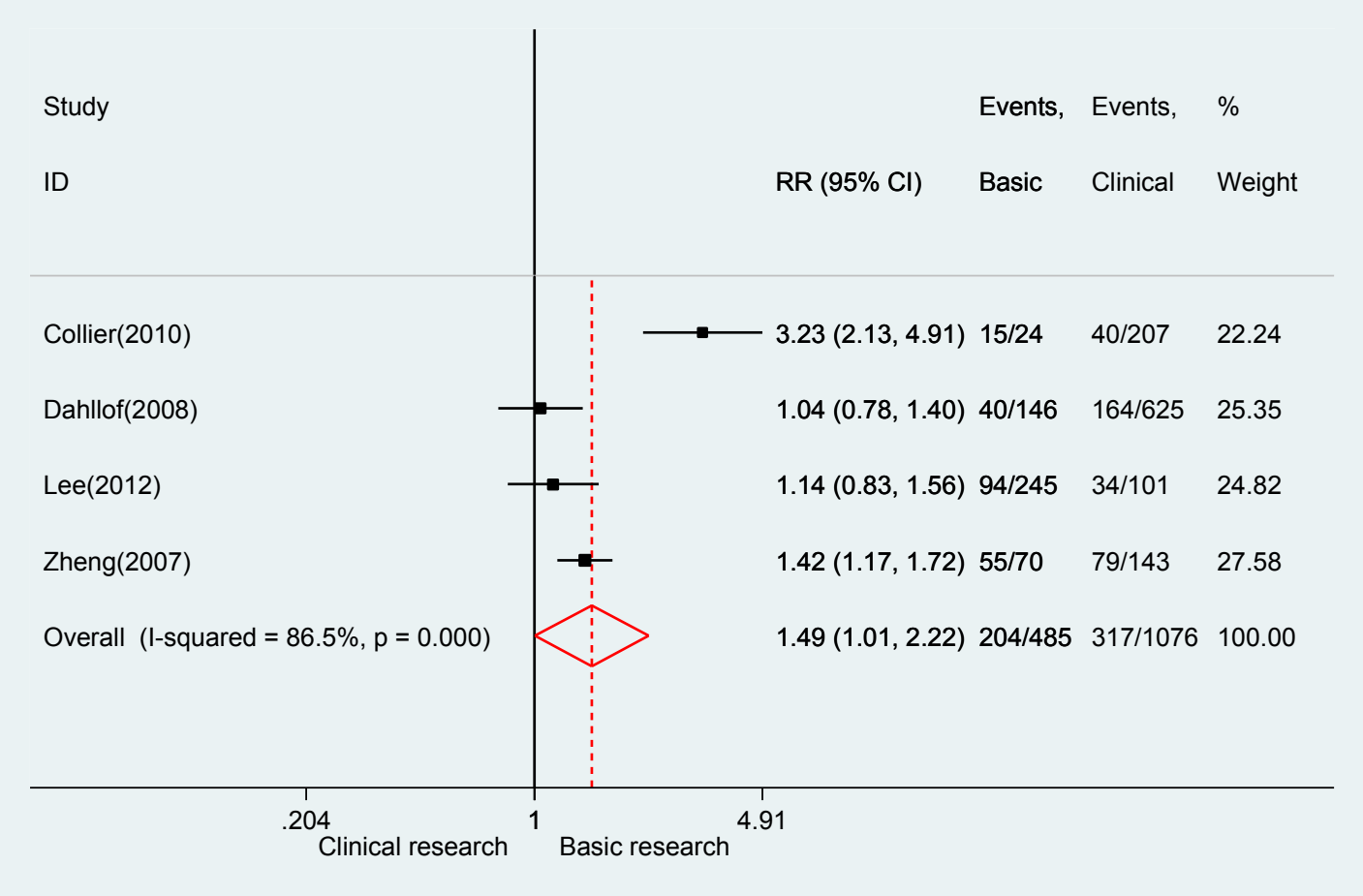


(7).

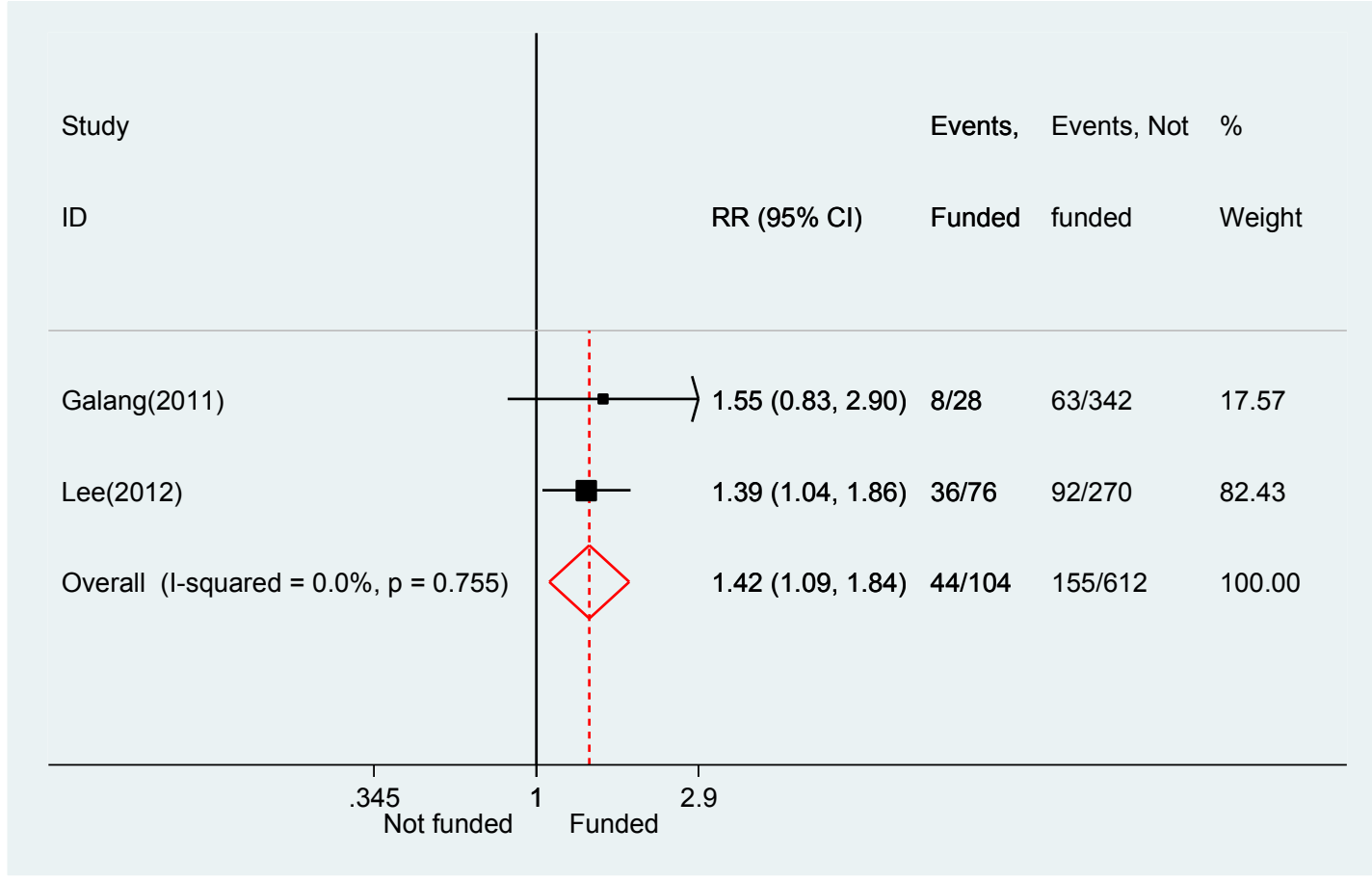

(8).

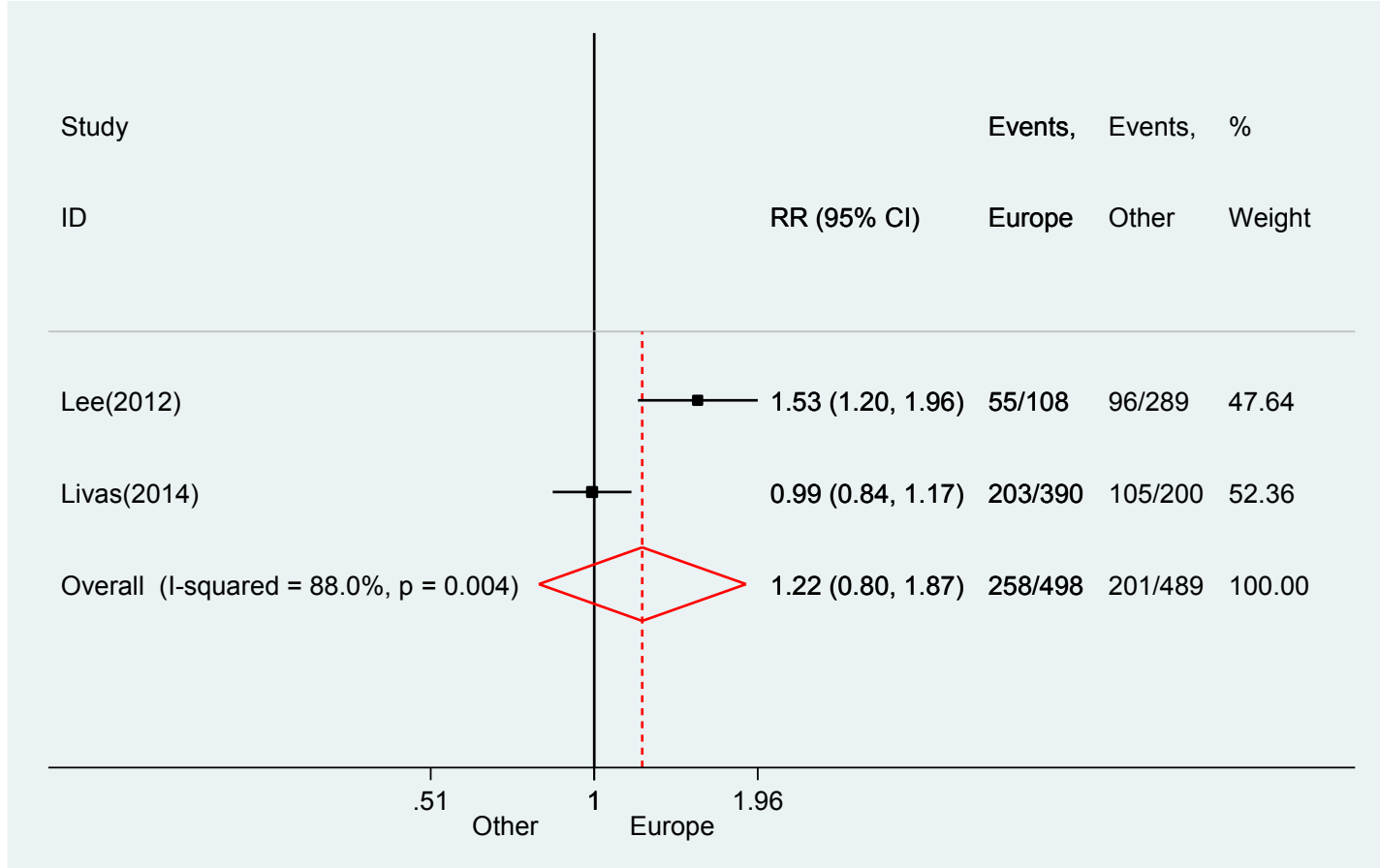


(9).



Appendix E. Forest plot for Pooled FPR of RCT abstracts only.

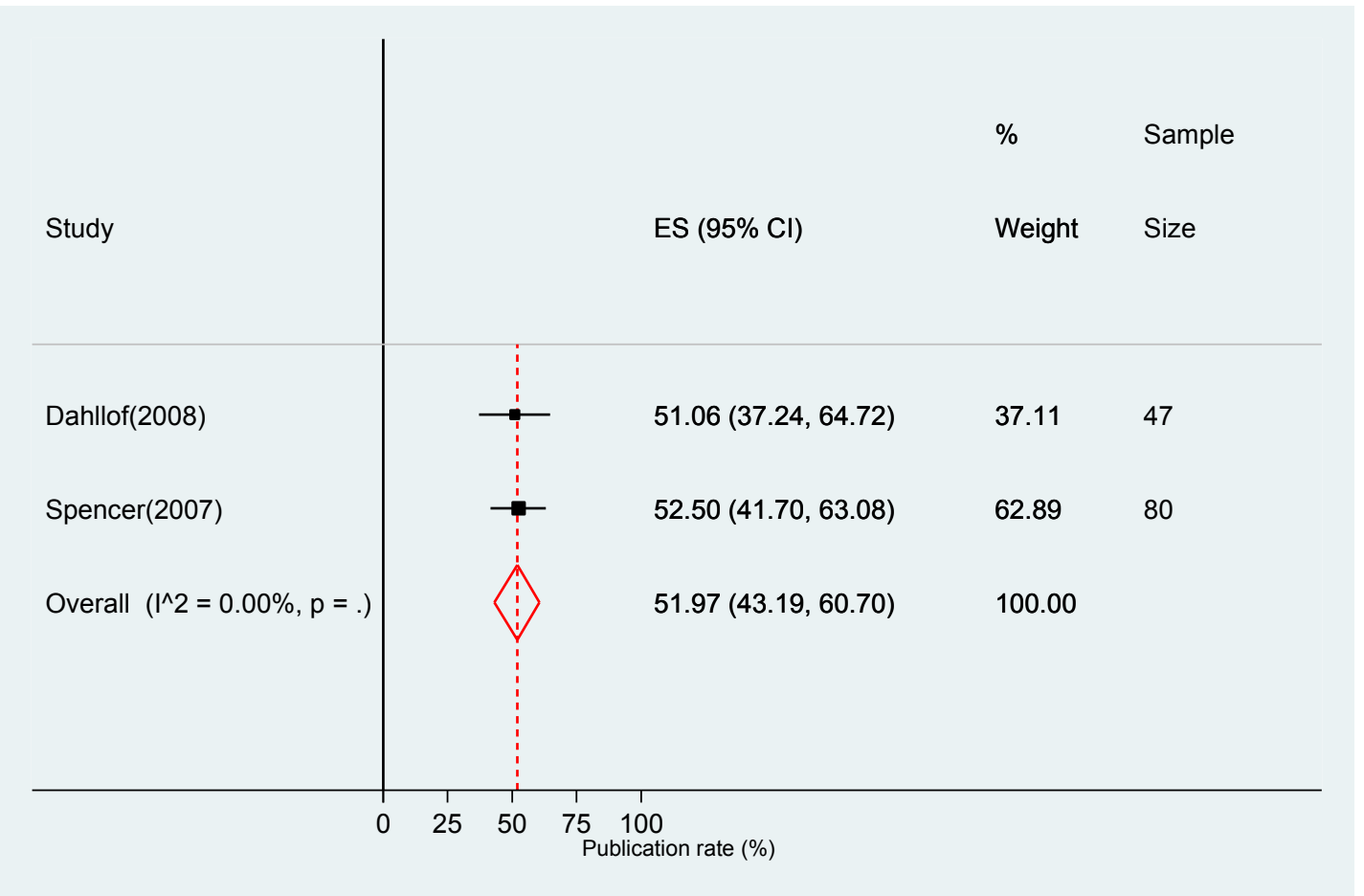

